\title{
Monitoring deep-tissue oxygenation with a millimeter-scale ultrasonic implant
}

\author{
Soner Sonmezoglu ${ }^{1 凶}$, Jeffrey R. Fineman ${ }^{2,3}$, Emin Maltepe $^{2,3}$ and Michel M. Maharbiz $\mathbb{1}^{1,4,5 凶}$
}

\begin{abstract}
Vascular complications following solid organ transplantation may lead to graft ischemia, dysfunction or loss. Imaging approaches can provide intermittent assessments of graft perfusion, but require highly skilled practitioners and do not directly assess graft oxygenation. Existing systems for monitoring tissue oxygenation are limited by the need for wired connections, the inability to provide real-time data or operation restricted to surface tissues. Here, we present a minimally invasive system to monitor deep-tissue $\mathrm{O}_{2}$ that reports continuous real-time data from centimeter-scale depths in sheep and up to a 10-cm depth in ex vivo porcine tissue. The system is composed of a millimeter-sized, wireless, ultrasound-powered implantable luminescence $\mathrm{O}_{2}$ sensor and an external transceiver for bidirectional data transfer, enabling deep-tissue oxygenation monitoring for surgical or critical care indications.
\end{abstract}

T issue oxygenation is a critical determinant of organ function. In clinical settings, tracking oxygenation is limited to indirect approaches with suboptimal utility. In the context of organ transplantation ${ }^{1}$, vascular complications, such as hepatic artery thrombosis following orthotopic liver transplantation, frequently lead to graft ischemia, dysfunction and $\operatorname{loss}^{2}$. The ability to continuously monitor graft oxygenation status via a wireless sensor placed at the time of transplant would augment our abilities to track tissue perfusion, allowing timely intervention, and would help differentiate parenchymal rejection from graft vascular disease in the setting of graft dysfunction.

Most clinically available direct $\mathrm{O}_{2}$ monitoring systems rely on electrochemical sensors (Clark-type electrodes) ${ }^{3}$ and luminescence probes ${ }^{4}$. Clark-type electrodes consume $\mathrm{O}_{2}$, which potentially confounds accurate measurement of tissue $\mathrm{O}_{2}$, especially at low $\mathrm{O}_{2}$ concentrations, and are not well suited for long-term measurements due to their susceptibility to biofouling ${ }^{3}$. This led to the development of luminescence $\mathrm{O}_{2}$ probes. These probes, although easy to use and accurate, are invasive and fragile and currently rely on wired connections, limiting their use in the hospital environment. Fluorine magnetic resonance imaging ${ }^{5}$ and electron paramagnetic resonance spectroscopy ${ }^{6}$ have also been used to directly probe local $\mathrm{O}_{2}$ content in vivo. However, these methods suffer from an inability to provide real-time data, as they require long scanning times to quantify $\mathrm{O}_{2}$ concentration with sufficient resolution.

As an alternative to direct $\mathrm{O}_{2}$-sensing approaches, near-infrared spectroscopy ${ }^{7,8}$ has demonstrated the ability to quantify tissue $\mathrm{O}_{2}$ saturation levels. However, the use of noninvasive near-infrared spectroscopy systems, especially in deep tissues, is limited by the penetration depth of near-infrared light. An implantable wireless oximeter has demonstrated regional $\mathrm{O}_{2}$ saturation measurements from just below the skin in an untethered, freely moving mouse in a cage; the system relied on near-field electromagnetic (EM) waves for wireless power transfer, restricting it to shallow operation'.

Ultrasound (US) linkage has recently been explored as an attractive option for millimeter-scale deep-tissue implants ${ }^{10,11}$. In contrast to EM waves, US allows for wireless power and data transfer via pressure waves with millimeter and submillimeter wavelengths (1-10-MHz US carrier frequency). As a comparison, $2-\mathrm{MHz}$ US waves have a wavelength of $0.75 \mathrm{~mm}$, while 2-GHz EM waves have a wavelength of $25 \mathrm{~mm}$; this enables efficient coupling to miniaturized implants. In addition, US experiences lower attenuation in soft tissues (for example, US attenuates $\sim 1-2 \mathrm{~dB} \mathrm{~cm}^{-1}$ at $2 \mathrm{MHz}$; EM attenuates $\sim 10-12 \mathrm{~dB} \mathrm{~cm}^{-1}$ at $\left.2 \mathrm{GHz}\right)^{12}$ and consequently has a higher FDA regulatory limit for power flux density (US, $720 \mathrm{~mW} \mathrm{~cm}^{-2}$; $\left.\mathrm{EM}, \sim 10 \mathrm{~mW} \mathrm{~cm}^{-2}\right)^{13,14}$. Unlike that of EM waves, US power transfer through bone is more challenging because US attenuation in bone is more than an order of magnitude higher than in soft tissue, and reflections and scattering occur at the soft tissue-bone interface ${ }^{15}$.

In recent years, wireless systems based on ultrasonic millimeter-sized implants have demonstrated electrical recording ${ }^{10}$ from and stimulation ${ }^{11}$ of the sciatic nerve in an anesthetized rat model and tumor oxygenation ${ }^{16}$ and photodynamic tumor therapy ${ }^{17}$ in an anesthetized mouse model. Here, we present an ultrasonic wireless implant system for continuous real-time $\mathrm{O}_{2}$ measurements at centimeter-scale depths demonstrated in a clinically relevant anesthetized sheep model, showing promise of avoiding the drawbacks of the current $\mathrm{O}_{2}$-sensing technologies mentioned above. The system uses an $\mathrm{O}_{2}$ sensor implant that incorporates a single piezoelectric ceramic and a luminescence sensor consisting of a $\mu \mathrm{LED}$, an $\mathrm{O}_{2}$-sensing film, an optical filter and a state-of-the-art integrated circuit (IC) ${ }^{18}$. The sensor operates on the same readout principle, phase luminometry, as most luminescence sensors ${ }^{19}$ and probes ${ }^{20}$, but with much lower power consumption and competitive or better $\mathrm{O}_{2}$ resolution than these sensors and probes. This is achieved by compact integration of the sensor components and a custom IC. Wireless power and bidirectional data transfer are enabled using a single US link from an external transceiver. The use of a single link protocol combined with the tight integration of wireless sensor components results in a very small sensor volume $\left(4.5 \mathrm{~mm}^{3}\right)$. The small volume and lightweight construction $(\sim 17.4 \mathrm{mg})$ provide potential capabilities for use with minimal tissue damage. The system

'Department of Electrical Engineering and Computer Sciences, University of California, Berkeley, Berkeley, CA, USA. ${ }^{2}$ Department of Pediatrics, University of California, San Francisco, San Francisco, CA, USA. ${ }^{3}$ nitiative for Pediatric Drug and Device Development, San Francisco, CA, USA. ${ }^{4}$ The UC BerkeleyUCSF Graduate Program in Bioengineering, University of California, Berkeley, Berkeley, CA, USA. ${ }^{5}$ Chan Zuckerberg Biohub, San Francisco, CA, USA.

凶e-mail: ssonmezoglu@berkeley.edu; maharbiz@berkeley.edu 

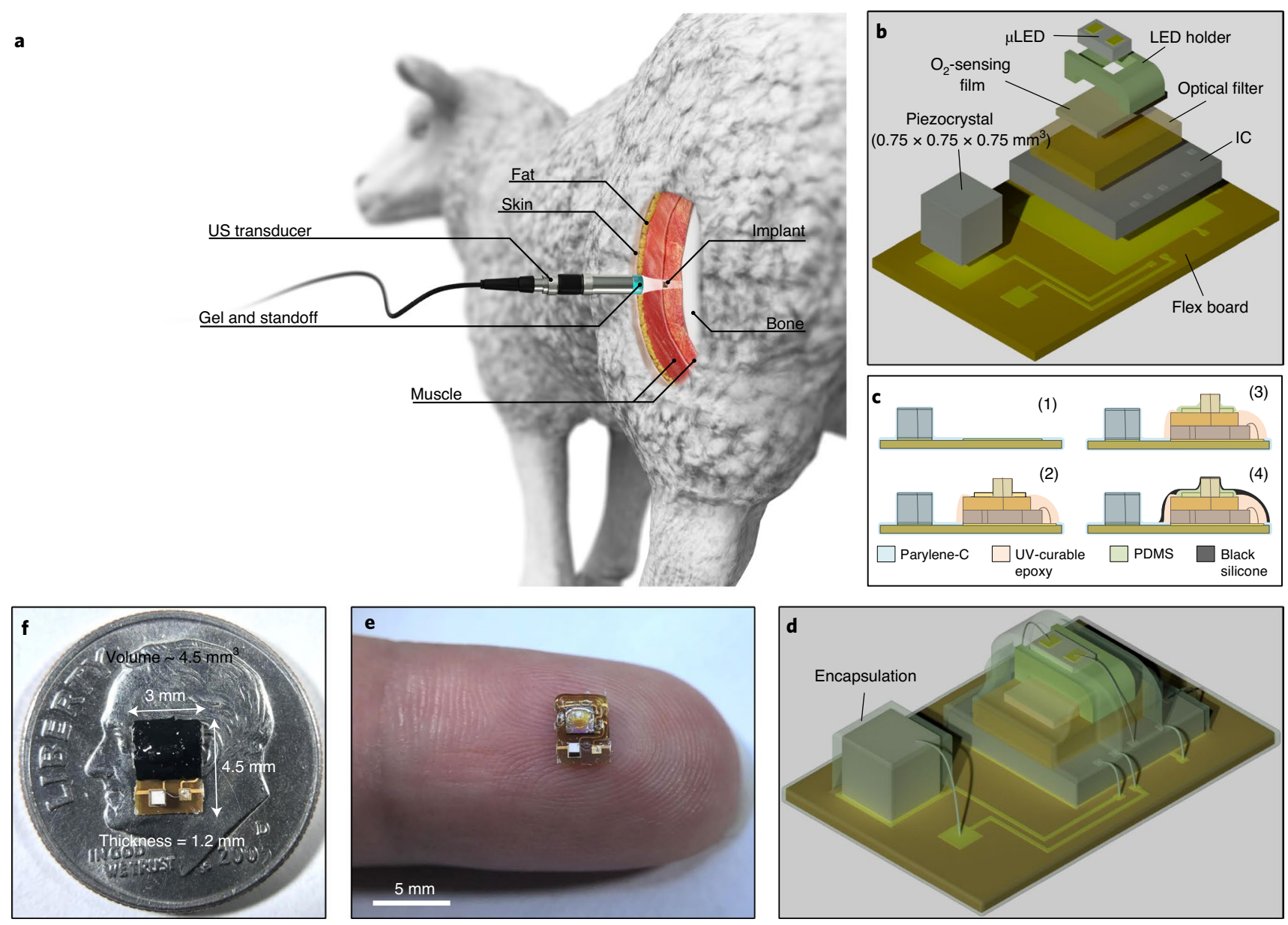

Fig. 1 | Wireless $\mathrm{O}_{2}$-monitoring system overview. a, Schematic of the system as demonstrated in this paper for local tissue $\mathrm{O}_{2}$ monitoring in sheep. The free-floating wireless $\mathrm{O}_{2}$ implant is surgically placed beneath the biceps femoris muscle, and the wound is closed with sutures. The external US transducer, placed on top of the closed surgical site, establishes a wireless acoustic link to the implant. The external transducer powers the implanted sensor by delivering acoustic energy through the tissue and then listens for backscatter reflections from the sensor's piezoelectric crystal, in which $\mathrm{O}_{2}$ data are encoded. The external transducer is driven by a custom mixed signal system, including decoding and storage of the wireless $\mathrm{O}_{2}$ data received by the external transducer. $\mathbf{b}$, An expanded view of the wireless sensor platform, including a lead zirconate titanate (PZT) piezocrystal and a luminescence sensor, consisting of a $\mu \mathrm{LED}$, a 3D-printed $\mu \mathrm{LED}$ holder, an $\mathrm{O}_{2}$-sensing film, an optical filter and an IC. c, The following steps were used for wireless sensor fabrication: (1) a piezocrystal was bonded with conductive silver epoxy, wire-bonded to a flexible printed circuit board (PCB) and encapsulated with parylene- $C_{;}(2)$ other sensor components were assembled on the flex board, and only the regions where the wire bonds are located were encapsulated with ultraviolet (UV)-curable epoxy; (3) the small gap ( $50 \mu \mathrm{m})$ between the film and the $\mu$ LED holder was filled by PDMS and (4) sensor parts excluding the piezocrystal were encapsulated with highly $\mathrm{O}_{2}$-permeable black silicone. $\mathbf{d}, \mathbf{e}$, Schematic (d) and photograph of the wireless sensor before black silicone encapsulation and size comparison to a finger (e); scale bar, $5 \mathrm{~mm}$. f, Top view of the $4.5-\mathrm{mm}^{3}$ packaged wireless sensor with the piezocrystal at the bottom, the luminescence sensor at the top and a size comparison to a United States dime.

operation is demonstrated in vitro in distilled water, PBS and human serum, ex vivo in porcine tissue and in vivo in sheep.

\section{Results}

A custom integrated circuit and a single ultrasonic link enable a complete wireless optical sensor in a volume of $4.5 \mathrm{~mm}^{3}$. An ultrasonic transceiver directs US energy from outside of the body toward an implant placed in muscle or deep tissue (Fig. 1a). This wireless acoustic link provides power to the sensor and allowed bidirectional data transmission. A custom mixed signal system drives the external transducer. The implant consists of a piezoelectric crystal for energy collection and communication coupled to a luminescence sensor for $\mathrm{O}_{2}$ detection.

The entire implant is manufactured with standard medical implant processes. The implant (Fig. 1b) consists of a piezoelectric crystal $\left(750 \times 750 \times 750 \mu \mathrm{m}^{3}\right)$, a $\mu \mathrm{LED}$, an $\mathrm{O}_{2}$-sensing film, an optical filter, an IC and a holder providing mechanical support during wire bonding of the $\mu \mathrm{LED}$. To assemble the sensor, a piezocrystal is attached and then encapsulated with parylene-C; the remaining components are then assembled on the flex board (Fig. 1c). Wire bonds are encapsulated with UV-curable epoxy, which was chosen due to its high bond strength. Finally, the sensor part is coated with black silicone to avoid background interference by the luminescence of tissue or blood ${ }^{21}$. The implant (Fig. 1d-f) measures $3 \times 4.5 \times 1.2 \mathrm{~mm}^{3}$, occupies a volume of $4.5 \pm 0.5 \mathrm{~mm}^{3}$ and has a detection volume of $\sim 0.26 \mathrm{~mm}^{3}$. The piezo resonant frequency determines the US link carrier frequency, as this frequency is set by the crystal thickness and aspect ratio ${ }^{22}$; crystal geometry was chosen to maintain a reasonable trade-off between the frequency-dependent acoustic loss in tissue, the power harvesting capacity and the impact on total implant size.

A complete biocompatible phase luminometric $\mathrm{O}_{2}$ optrode is built into the implant. The biocompatible $\mathrm{O}_{2}$-sensing film (Fig. 2a) 


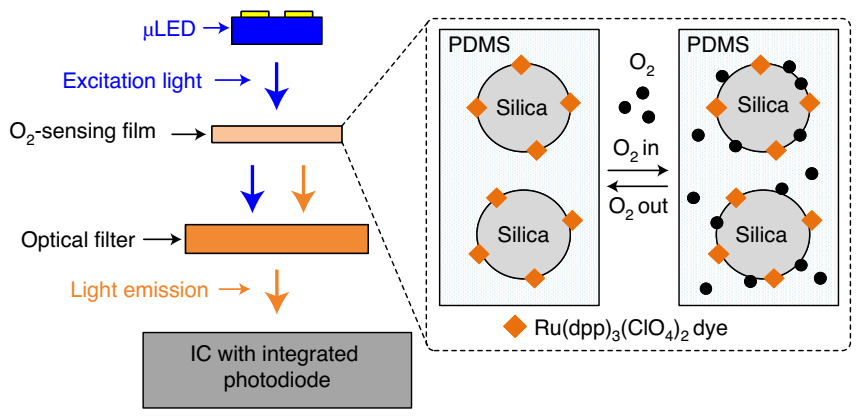

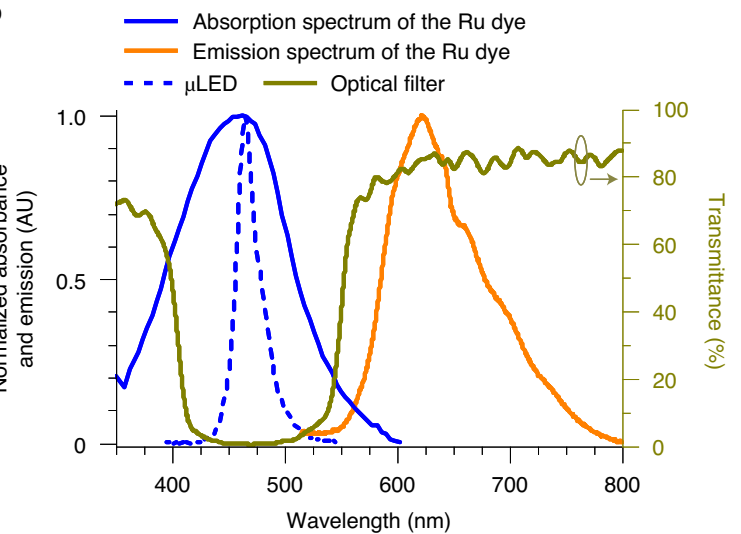

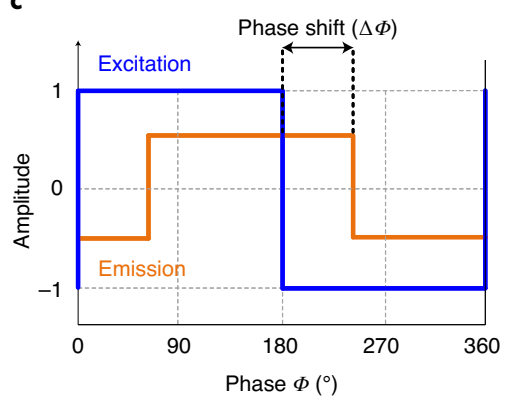

d

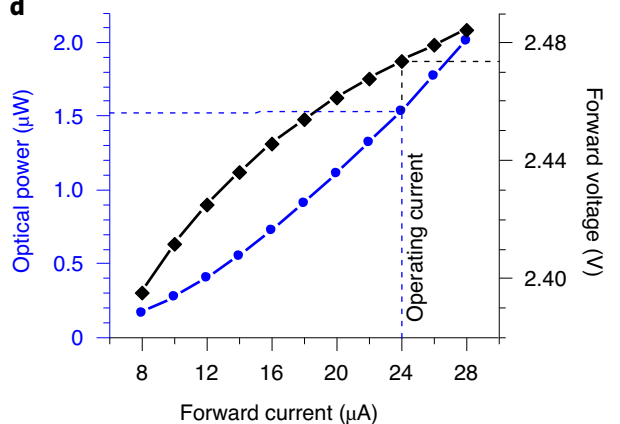

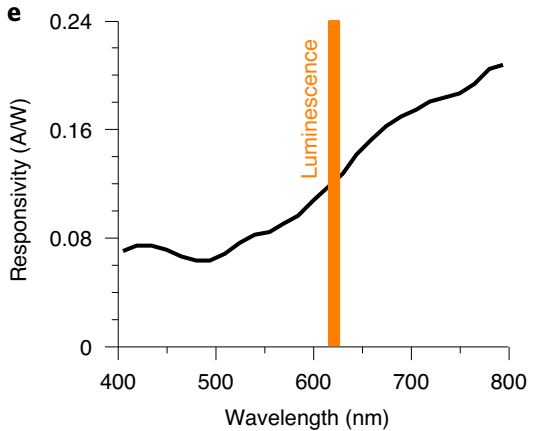

f

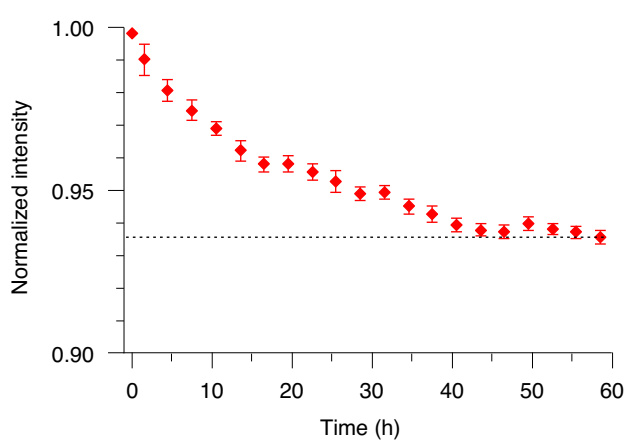

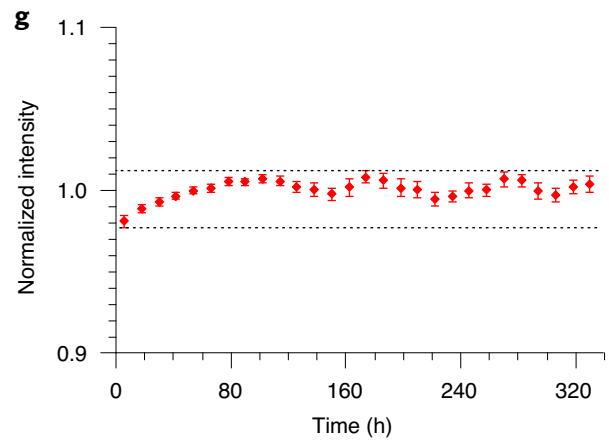

Fig. 2 | Biocompatible $\mathrm{O}_{2}$-sensing film, operating principle of the luminescence $\mathrm{O}_{2}$ sensor and its optical characterization. $\mathrm{a}$, An expanded cross-sectional view of the $\mathrm{O}_{2}$ sensor. The inset illustrates a model of the locus of ruthenium dye and $\mathrm{O}_{2}$ molecules in silica-containing PDMS. The orange squares and black circles represent the ruthenium dye and $\mathrm{O}_{2}$ molecules, respectively. The dye-adsorbed silica particles were dispersed in PDMS. b, Normalized absorption and emission spectra of the ruthenium dye in the $\mathrm{O}_{2}$-sensing film, along with the normalized emission spectrum of the blue $\mu \mathrm{LED}$ and transmission spectrum of the optical filter. $\mathbf{a}, \mathbf{b}$, In operation, the $\mu \mathrm{LED}$, placed on the sensor platform to illuminate the film, produces light with a peak intensity at $\sim 465 \mathrm{~nm}$ that excites the ruthenium dye. The excited dye emits luminescence with a peak at $621 \mathrm{~nm}$. An optical filter suppresses excitation light and transmits luminescence, enabling emission detection by an IC with an integrated photodiode. c, Illustration of frequency domain excitation and emission signals. d, Current-voltagelight output characteristics of the blue $\mu$ LED $(n=1)$. e, Responsivity spectrum of an integrated, nwell/psub photodiode with an active area of $300 \times 300 \mu m^{2}$ and a 0.6-V reverse-bias voltage. The orange-shaded area highlights wavelength ranges with strong luminescence emission. $\mathbf{f}$, Photobleaching of ruthenium dye in the $\mathrm{O}_{2}$-sensing film under continuous square-wave illumination with a peak excitation light power of $\sim 1.53 \mu \mathrm{W}$ at room temperature in air $\left(21 \% \mathrm{O}_{2}\right.$ ) for a 60 -h period ( $n=1$ sensor). $\mathbf{g}$, Normalized luminescence intensity of ruthenium dye versus time after immersion of the same $\mathrm{O}_{2}$ sensor $(n=1)$ used for the photobleaching test in PBS solution at $37^{\circ} \mathrm{C}$ in room air. During the test, the sensor was operated with the same operating conditions as in the photobleaching test. The continuously collected data were averaged every $3 \mathrm{~h}(\mathbf{f})$ and $12 \mathrm{~h}(\mathbf{g})$ and are presented as the mean $\pm 1 \mathrm{~s} . d$. for each data point.

consists of polydimethylsiloxane (PDMS) containing silica particles with surface-adsorbed ruthenium dyes ${ }^{23}$. Upon excitation at $\sim 465 \mathrm{~nm}$, the ruthenium dyes emit light with a peak intensity at $\sim 621 \mathrm{~nm}$ (Fig. 2b). The excited ruthenium dyes undergo collisional quenching with $\mathrm{O}_{2}$ molecules, leading to a reduction in luminescence intensity and lifetime ${ }^{21}$. Both the intensity $(I)$ and lifetime $(\tau)$ depend on $\mathrm{O}_{2}$ concentration according to the Stern-Volmer equation ${ }^{19}: I_{0} / I=\tau_{0} / \tau=1+K_{\mathrm{SV}}\left[\mathrm{O}_{2}\right]$, where $I_{0}$ and $\tau_{0}(\sim 6.4 \mu \mathrm{s})$ are the intensity and lifetime at an $\mathrm{O}_{2}$ concentration of 0 , respectively, and
$K_{\mathrm{sV}}$ is the Stern-Volmer constant. Either intensity or lifetime can be measured to compute $\mathrm{O}_{2}$; lifetime is independent of variations in light source intensity, dye concentration, inner filter effects and photobleaching (to a large extent), all of which are limitations of intensity-based sensors ${ }^{24,25}$.

This sensor operates on the principle of phase luminometry, wherein the phase shift $(\Delta \Phi)$ between the excitation and emission light is measured to determine the luminescence lifetime. During operation, the emitted light is square-wave modulated at a 
a

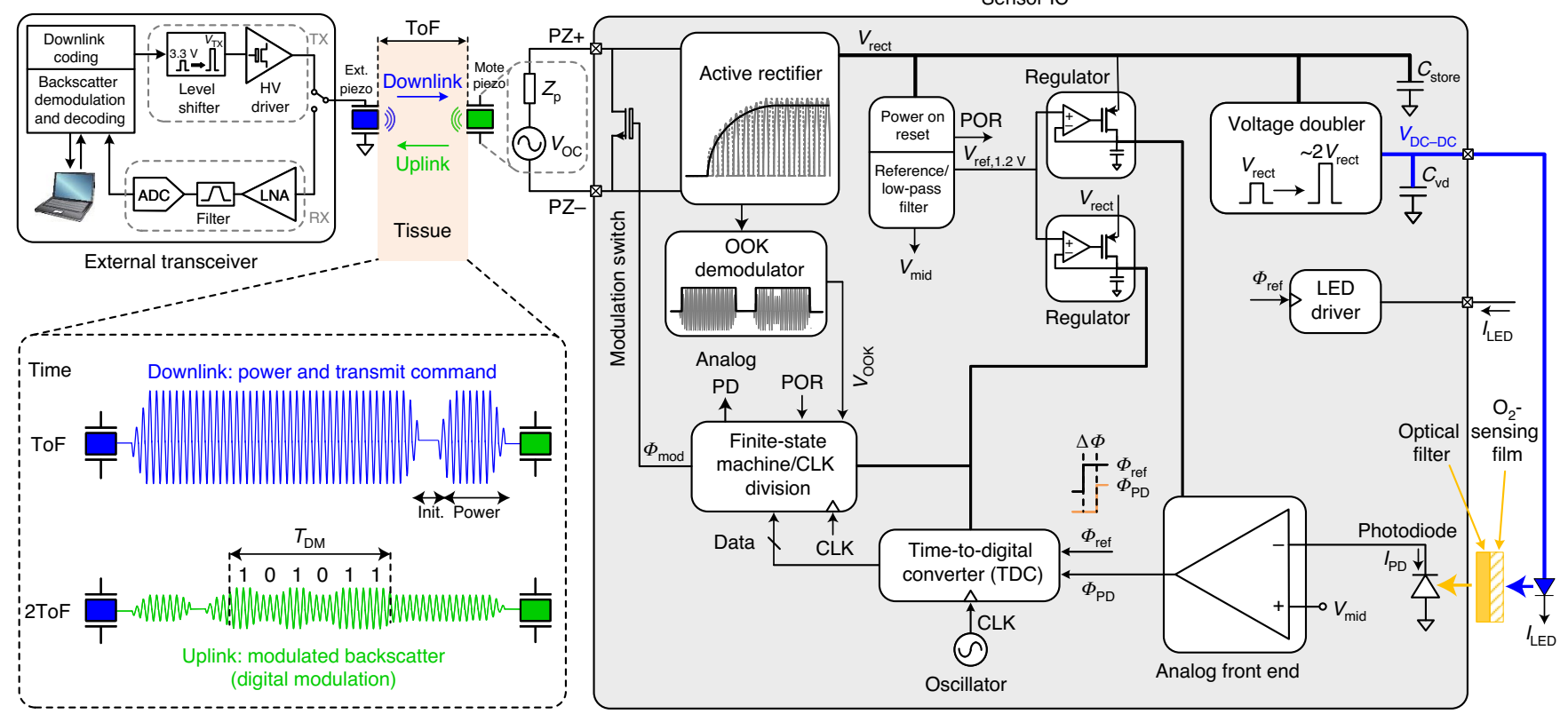

b

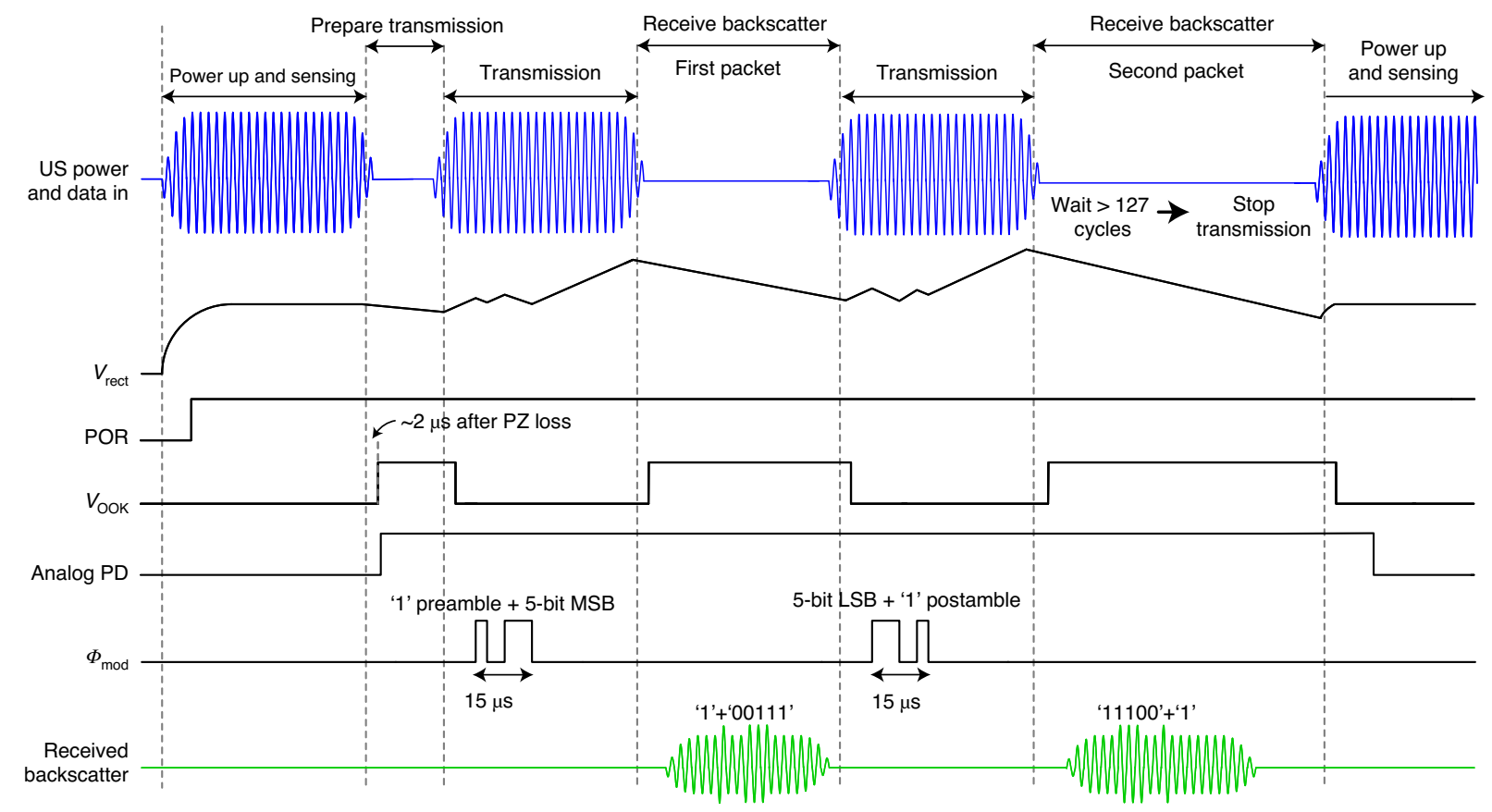

Fig. 3 | Entirely wireless $\mathrm{O}_{2}$-monitoring system block diagram. $\mathbf{a}$, The external transceiver is shown in the top left, the US link is shown in the top middle and the wireless sensor is shown on the right. Top left, the external transceiver consists of TX and RX paths, where the TX path encodes downlink data onto a 2-MHz carrier. During TX operation, a level shifter boosts a low-voltage TX signal from a digital controller, and a high-voltage pulser drives an external piezo transducer. The RX path is enabled when the TX path is disabled. The reflected US backscatter from the sensor's piezocrystal is captured by the same external piezo transducer and is digitized by the RX chain. Top middle, the external piezo coupled to the outside surface of tissue produces US waves traveling through tissue; these arrive at the sensor after one time-of-flight (ToF). The downlink provides power and a transmit command for the sensor. The uplink consists of amplitude-modulated backscattered US waves that arrive at the external piezo 2 ToF after being sent during TX. Right, the sensor IC architecture; CLK, clock. b. Timing diagram. The IC rectifies electrical power collected by the sensor's piezo, and the POR initializes the $\mathrm{O}_{2}$-sensing operation. The on-off keying (OOK) demodulator detects the downlink US envelope, producing a notch. The first notch starts uplink transmission. Two data packets are transmitted via digital amplitude modulation of the US backscatter; the first packet contains five MSBs and a 1-bit preamble. The uplink data are received by the external piezo when the external transceiver is switched to RX. The uplink transmission stops when the third notch duration is longer than $\sim 64 \mu \mathrm{s}$ (127 oscillations of a 2-MHz carrier). The IC circuitry is duty cycled during uplink transmission to reduce energy consumption.

fixed frequency $\left(f_{\text {op }}=20 \mathrm{kHz}\right)$ (Fig. $2 \mathrm{c}$ ), exciting the ruthenium dye with a peak excitation power of $\sim 1.53 \mu \mathrm{W}$, resulting in an average power intensity of $\sim 4.9 \mu \mathrm{W} \mathrm{mm} \mathrm{mm}^{-2}$ at the film surface (Fig. $2 \mathrm{~d}$ ). At $37^{\circ} \mathrm{C}$ in room air, the ruthenium dye produced an emission with a typical average power density of $\sim 8 \mathrm{nW} \mathrm{mm}^{-2}$ at the same $f_{\text {op }}$, but with a $\Delta \Phi$ relative to the phase of the excitation light. After 
the excitation light is suppressed by an optical filter, emission is detected by a reverse-biased, on-chip photodiode with a responsivity of $\sim 0.12 \mathrm{~A} / \mathrm{W}$ at $\sim 621 \mathrm{~nm}$ peak emission (Fig. 2e). The resulting $\Delta \Phi=\tan ^{-1}\left(2 \pi f_{\mathrm{op}} \tau\right) \approx \omega_{\mathrm{op}} \tau$ for $\omega_{\mathrm{op}} \tau \ll 1$ and is dependent on the luminescence lifetime that, in turn, is related to $\mathrm{O}_{2}$ via the SternVolmer equation.

Ruthenium dye photobleaching was evaluated using a fully packaged sensor continuously operated in room air and at room temperature for a 60 -h period. The luminescence intensity decreased rapidly to $\sim 96.8 \%$ of its initial value in the first $10 \mathrm{~h}$ and at a slower rate from $\sim 96.8 \%$ to $\sim 93.6 \%$ in the next $50 \mathrm{~h}$ (Fig. $2 \mathrm{f}$ ), indicating that the sensor could be operated with $1 \%$ duty cycle, corresponding to $14.4 \mathrm{~min}$ of continuous operation in a single day, for $250 \mathrm{~d}$ with an only $\sim 6.4 \%$ intensity drop. After the bleaching test, a long-term test of the same sensor immersed in $1 \times \mathrm{PBS}$ at $37^{\circ} \mathrm{C}$ was conducted in room air to evaluate dye leaching; fluctuation in luminescence intensity was within $\pm 1.7 \%$ and did not exhibit a decreasing trend in $14 \mathrm{~d}$ (Fig. $2 \mathrm{~g}$ ).

A custom IC drives sensor operation and communication for $<150 \mu \mathrm{W}$ average power consumption. A system block diagram is shown in Fig. 3 (see ref. ${ }^{18}$ for details). During operation, the controller driving the external transducer alternates between transmit (TX) and receive (RX) modes. When in TX mode, it drives the transducer with a $2-\mathrm{MHz}$ carrier wave onto which it encodes digital information in discrete pulses. The implant begins harvesting energy following the arrival of an US pulse; this energy is rectified and stored on the on-chip capacitor. The stored energy allows the implant to operate when the external transducer is in RX mode. The rectified voltage $\left(V_{\text {rect }}\right)$ is regulated at $1.2 \mathrm{~V}$. When the regulator voltage exceeds a predetermined level $(\sim 1 \mathrm{~V})$ during the power-up period, a power-on-reset (POR) signal is triggered to initialize the IC. After an initialization period (Supplementary Fig. 1), an LED driver drives the $\mu$ LED with a $24-\mu \mathrm{A}, 20-\mathrm{kHz}$ square-wave current, starting the $\mathrm{O}_{2}$-sensing operation. The $\mu$ LED excites the $\mathrm{O}_{2}$-sensitive dyes, producing luminescence. The light induces a photocurrent $\left(I_{\mathrm{PD}}\right)$ on the photodiode, which is converted to a voltage. The resulting AC voltage is compared to its DC component by an analog front end (AFE) for zero-crossing detection ${ }^{26}$, generating a time-delayed signal. A time-to-digital converter converts the time delay (phase difference, $\Delta \Phi)$ between the reference signal $\left(\Phi_{\text {ref }}\right)$ used to drive the $\mu$ LED and the luminescence signal $\left(\Phi_{\mathrm{PD}}\right)$ into 10-bit digital data. The 10-bit data are serialized and divided into two equal $15-\mu$ s-long data packets with a preamble and a postamble by a finite-state machine; the first packet contains the most significant bits (MSBs). The measured minimum detectable average optical power, yielding a signal-to-noise ratio (SNR) of 1 at a $1-\mathrm{Hz}$ bandwidth, was $\sim 1.3 \mathrm{pW}$ at $\sim 621 \mathrm{~nm}$ peak emission for the optical readout, dominated by the AFE noise. The SNR was $\sim 53 \mathrm{~dB}$ under a typical $\sim 6.7-\mathrm{nW} \mathrm{mm}^{-2}$ light power after the optical filter for the sensor, operated in room air at $37^{\circ} \mathrm{C}$.
An uplink data transmission begins when the demodulator detects a 'falling edge' in the US data input from the external transceiver, generating a notch $\left(V_{\mathrm{OOK}}\right)$. The notch serves as a reference to time synchronize the sensor IC and the external transceiver during uplink transmission; a data packet is transmitted after a notch. Data packets are encoded in the US reflections from the sensor's piezo and transmitted via backscatter amplitude modulation. Backscatter amplitude modulation is achieved by modulating the electrical load resistance $\left(R_{\text {load }}\right)$, in shunt with the piezo impedance $\left(Z_{\mathrm{p}}\right)$, through a modulation (transistor) switch controlled by $\Phi_{\text {mod }}$, changing the US reflection coefficient at the piezo boundary (Supplementary Fig. 2) and thus the backscatter amplitude ${ }^{27}$. When the switch is turned on to transmit the $\mathrm{O}_{2}$ data, the $R_{\text {load }}$ is reduced from a resistance higher than $80 \mathrm{k} \Omega$, depending on the IC power consumption and the rectifier input voltage amplitude, to $\sim 0.5 \mathrm{k} \Omega$ (switch-on resistance). The uplink transmission stops when the notch duration is longer than $\sim 64 \mu$ s.

The total area of the IC die is $\sim 3.84 \mathrm{~mm}^{2}$ (Supplementary Fig. 3). The minimum electrical power required for proper IC operation is $\sim 150 \mu \mathrm{W}$ during the $\mathrm{O}_{2}$-sensing phase. The AFE, LED driver, voltage doubler and time-to-digital converter are duty cycled off during uplink transmission, reducing IC power consumption to $\sim 22 \mu \mathrm{W}$ and avoiding the need for a large off-chip $C_{\text {store. }}$ The average power dissipation of the IC drops to less than $150 \mu \mathrm{W}$, including the rectifier's power conversion efficiency during operation, depending on the $\mathrm{O}_{2}$ sampling rate $\left(f_{\mathrm{s}}\right)$. The system $f_{\mathrm{s}}$ is externally controlled through the external transceiver.

During operation, the transceiver is switched from TX to RX mode to capture uplink data. The RX path decodes the backscatter, generating real-time $\mathrm{O}_{2}$ data. To avoid overlapping TX and RX pulses, the data packet duration $\left(T_{\mathrm{DM}}\right)$ is kept shorter than the round-trip ToF (2ToF) of an US pulse between the sensor's piezo and the external transducer, limiting the minimum operating depth. To overcome this limitation, the digital data are divided into two parts that are subsequently transmitted. See also Supplementary Fig. 4 for an alternative communication protocol for sensors implanted deeper than $5 \mathrm{~cm}$.

The system samples $\mathrm{O}_{2}$ at $350 \mathrm{~Hz}$ with a bit error rate of $<10^{-5}$ and a resolution of $<5.8 \mathrm{~mm} \mathrm{Hg} \mathrm{Hz} \mathbf{H z}^{-1 / 2}$ across the physiologically relevant $\mathrm{O}_{2}$ range $(0-100 \mathrm{~mm} \mathrm{Hg})$. The system was first characterized in a water tank (Fig. 4a); water has an acoustic impedance similar to that of soft tissue $(\sim 1.5 \mathrm{Mrayl})^{28}$. Measured waveforms and backscatter signal were recorded for the system operated at a depth of $5 \mathrm{~cm}$ and a $f_{\mathrm{s}}$ of $350 \mathrm{~Hz}$ using an acoustic field with a spatial-peak time-average intensity $\left(I_{\mathrm{SPTA}}\right)$ of $237 \mathrm{~mW} \mathrm{~cm}^{-2}(\sim 32.9 \%$ of the FDA safety limit; $I_{\text {SPTA }}$ derated is $720 \mathrm{~mW} \mathrm{~cm}^{-2}$ for diagnostic US) (Fig. 4b). The system exhibited a power transfer efficiency (PTE; Supplementary Notes) from the acoustic power at the implant's piezo surface to the IC's electrical input power of $20.4 \%$ and an US link PTE of $\sim 3.9 \%$, defined as the ratio of the IC's input power to the acoustic power emitted from the external transducer. Each data packet was $15 \mu$ s long (Fig. 4c); the first packet has a ' 1 ' preamble

Fig. 4 | In vitro characterization of the wireless $\mathrm{O}_{2}$-sensing system. $\mathbf{a}$, Wireless sensor operation in distilled water at $37 \pm 0.1^{\circ} \mathrm{C}$ (physiological temperature). The depth was set to $5 \mathrm{~cm}$, and water $\mathrm{O}_{2}$ levels were precisely controlled using two identical gas flow controllers and a commercial $\mathrm{O}_{2}$ probe (NEOFOX) during measurements. $\mathbf{b}$, Sensor waveforms and backscatter signal were recorded in the wireless measurement of a single $\mathrm{O}_{2}$ sample. c, Zoomed-in data packets show digital amplitude modulation of the US backscatter. d, Backscatter relative difference for $121,000 \mathrm{O}_{2}$ samples, showing a $\sim 41 \%$ MD. To detect each bit, which is either ' $O$ ' or ' 1 ', the amplitude of the backscatter signal in the data packets is compared to a threshold. The wireless system achieved an uplink BER $<10^{-5}$ ( 0 of 121,000 samples) in the measurement, demonstrating a robust data uplink. e, System response to various $\mathrm{O}_{2}$ concentrations. The measurement was performed at $350 \mathrm{~Hz} \mathrm{f}$ and a $5-\mathrm{cm}$ depth in the $\mathrm{O}_{2}$ range of 3.8-150 mm Hg. f, Allan deviation of the raw data (shown in Supplementary Fig. 6a). g,h, $\mathrm{O}_{2}$ sensor response to changes in $\mathrm{O}_{2}$ concentration in distilled water at $37^{\circ} \mathrm{C}$ before and after black silicone encapsulation ( $(\mathbf{g})$ and ethylene oxide (EtO) sterilization $(\mathbf{h})$. $\mathbf{i}$, Data from the $\mathrm{O}_{2}$ sensors $(n=2)$; one sensor was incubated in PBS and the other sensor was incubated in undiluted human serum at $37^{\circ} \mathrm{C}$ for $10 \mathrm{~d}$. The $2-\mathrm{min}_{2}$ data from the sensors operated at $350 \mathrm{~Hz} \mathrm{f}_{\mathrm{s}}$ were recorded at different times over $10 \mathrm{~d}$. Data for 2 min were averaged and are presented as the mean \pm 1 s.d. 
and 5-bit MSBs, and the second packet has 5-bit least significant bits (LSBs) and a ' 1 ' postamble. The system achieved a modulation depth (MD) of $\sim 41 \%$ and an uplink bit error rate (BER) $<10^{-5}(0$ of 121,000 samples) with the optimal threshold, minimizing BER (Fig. 4d).
The system response to various $\mathrm{O}_{2}$ concentrations and the Allan deviation of the data are illustrated in Fig. 4e,f. The system operated at $350 \mathrm{~Hz} f_{\mathrm{s}}$ exhibited an $\mathrm{O}_{2}$ sensitivity greater than $\sim 0.066^{\circ}$ $(\mathrm{mm} \mathrm{Hg})^{-1}$ and a phase $(\Phi)$ resolution less than $0.38^{\circ} \mathrm{Hz}^{-1 / 2}$, a

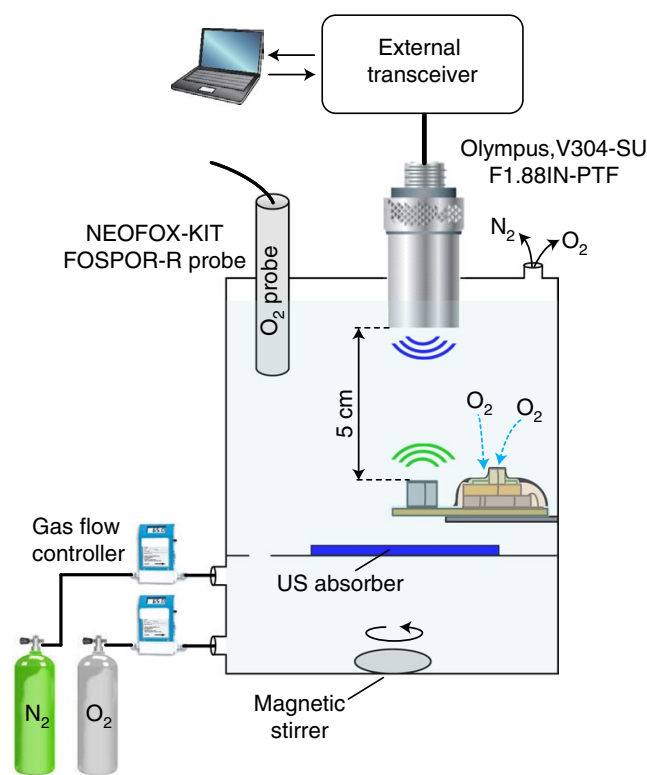

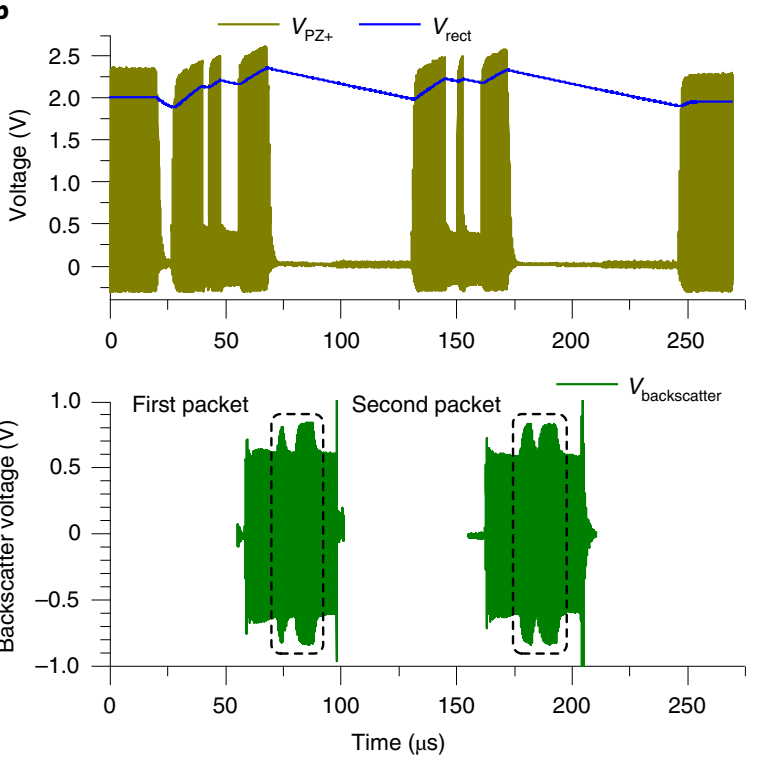

c
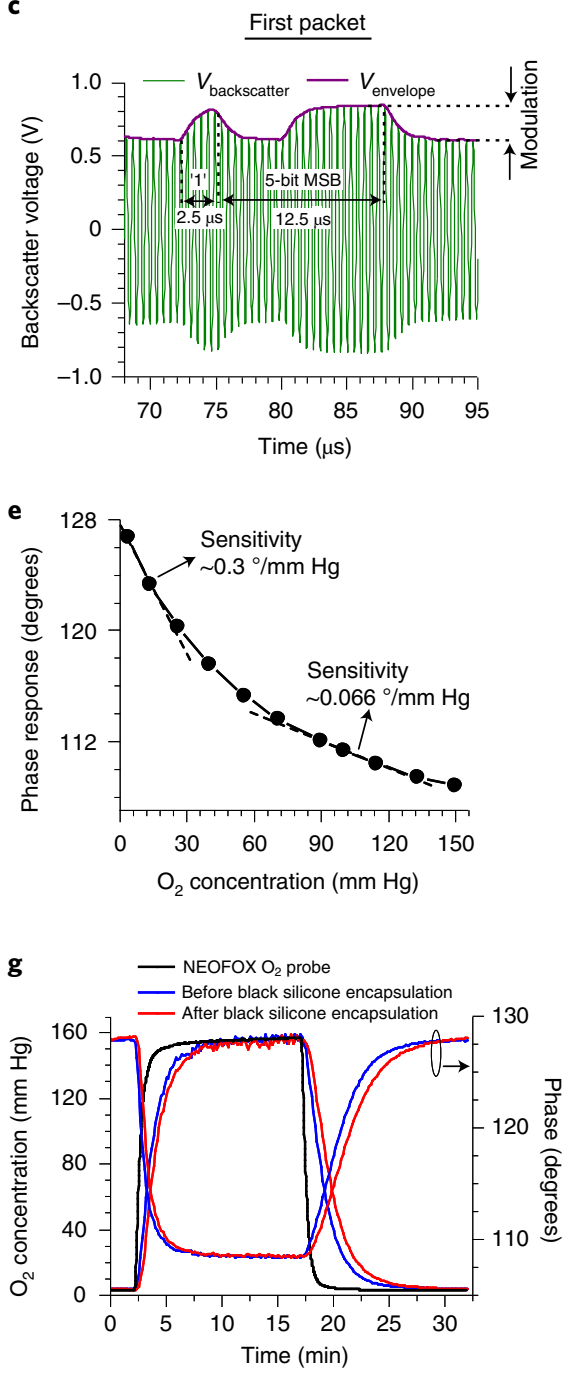
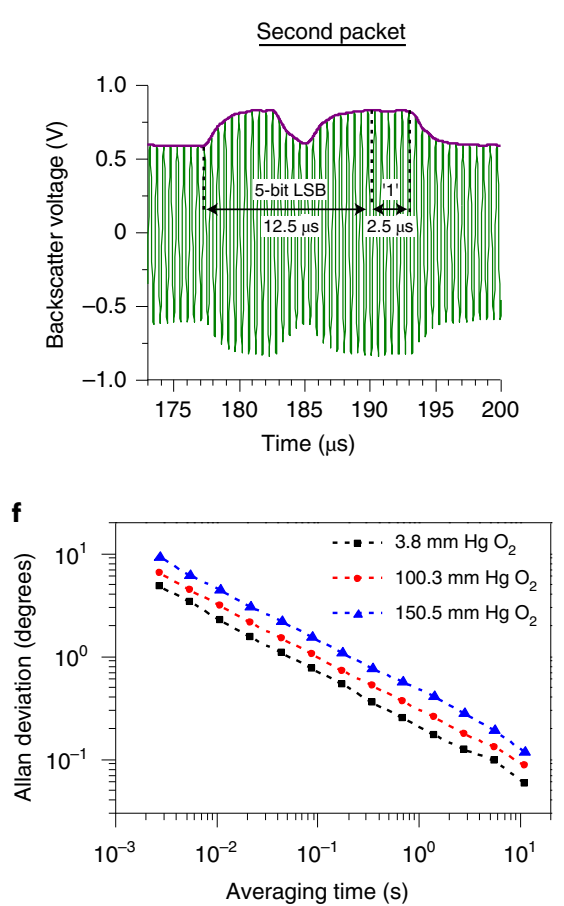

h

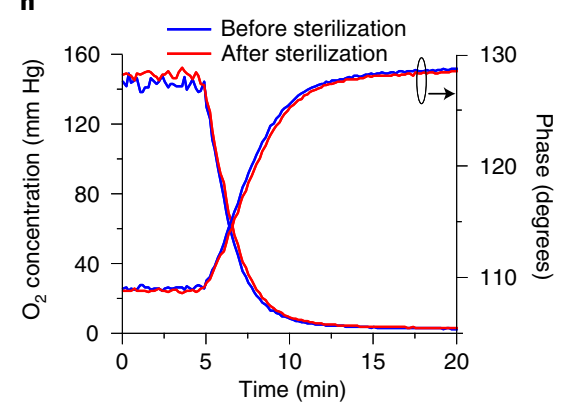

d
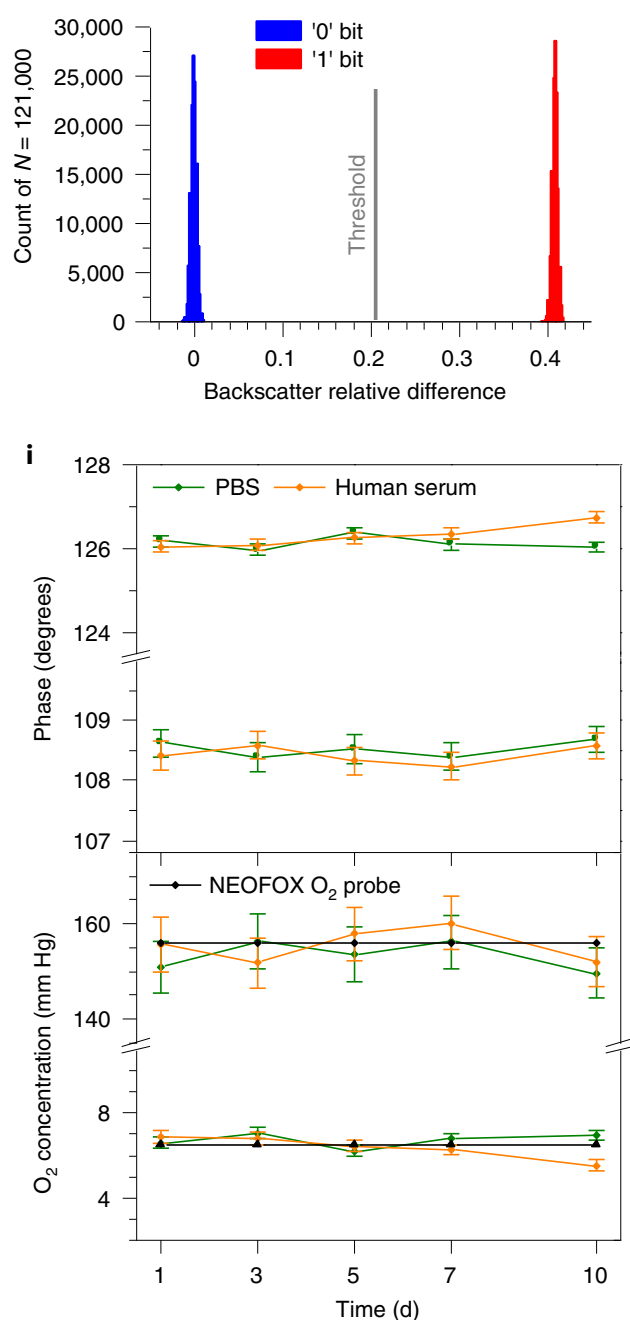


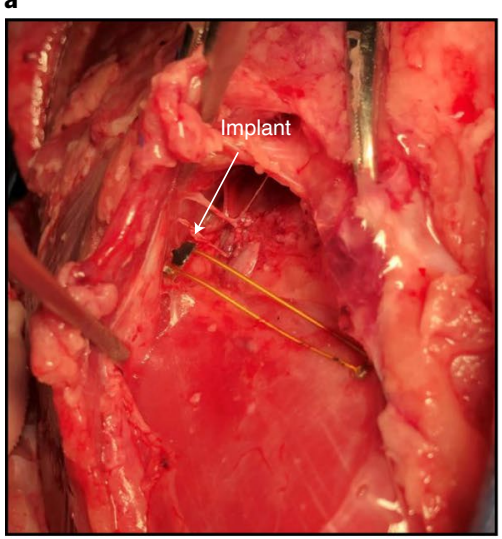

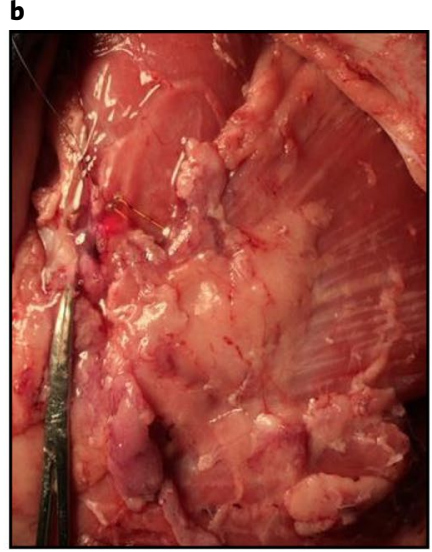

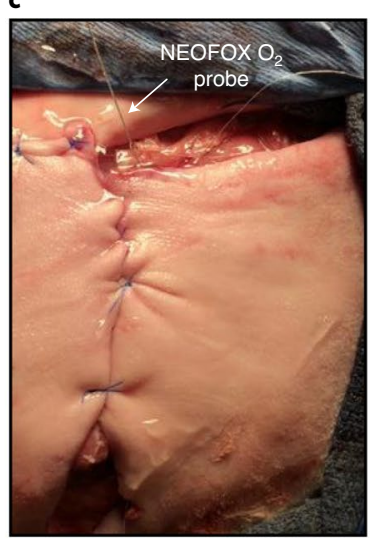

d

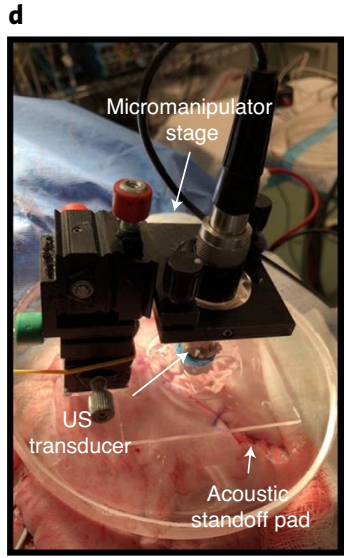

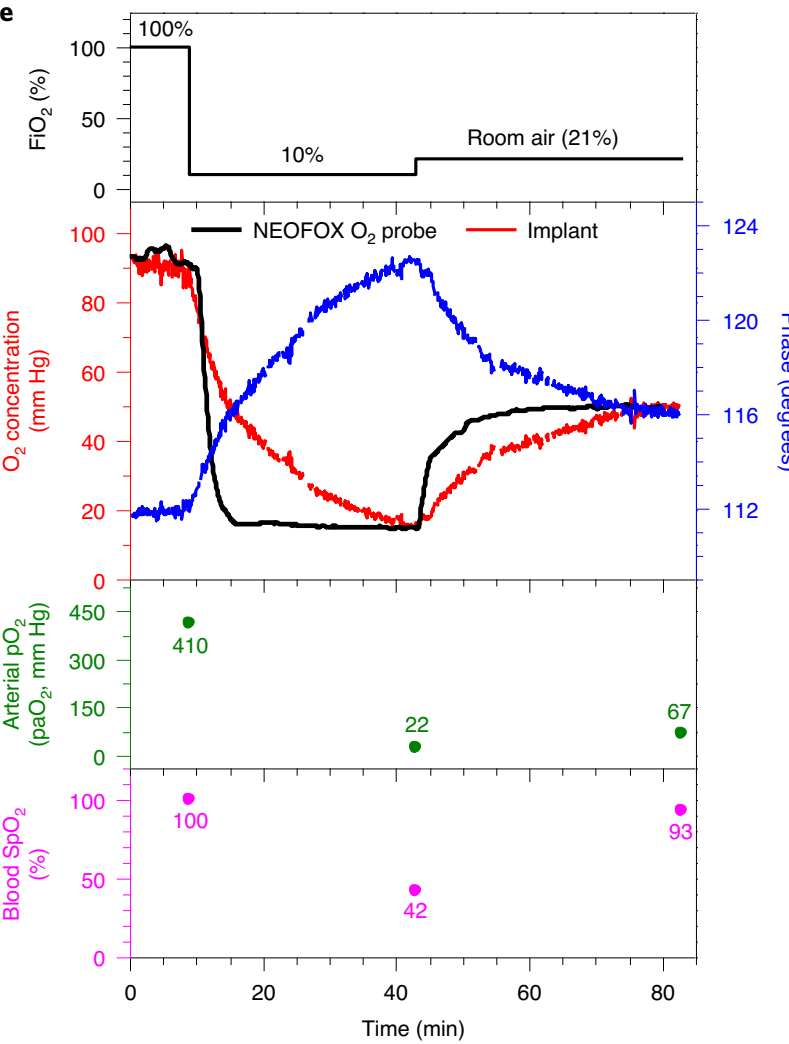

$\mathbf{f}$

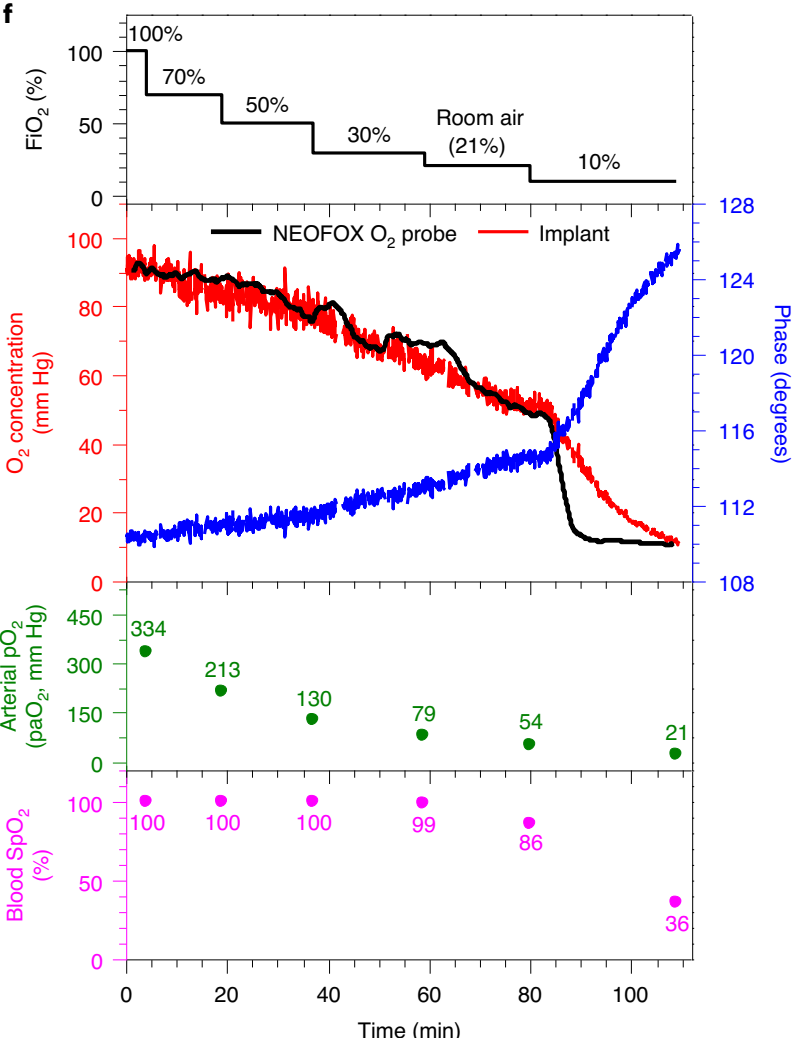

Fig. 5 | Surgical placement of and recording from the implantable, wireless $\mathrm{O}_{2}$ sensor under conditions of normoxia, hyperoxia and hypoxia.

a, The wireless sensor was placed underneath the biceps femoris muscle in anesthetized sheep following careful surgical dissection. $\mathbf{b}, \mathbf{c}$, The biceps femoris muscle was layered over the sensor, completely covering it (b), and the overlying skin was sutured using an interrupted approach (c). d, The micromanipulator stage housing the US transducer was placed on top of the skin layer on an acoustic standoff pad. e, The anesthetized animal was provided with $100 \%$ inspired $\mathrm{O}_{2}\left(\mathrm{FiO}_{2}\right)$ via an endotracheal tube followed by a hypoxic gas mixture of $10 \%$ O confirmation with an inline $\mathrm{O}_{2}$ detector, followed by ventilation with room air $\left(21 \% \mathrm{O}_{2}\right)$. Tissue $\mathrm{O}_{2}$ concentration readings were continuously monitored via the wireless $\mathrm{O}_{2}$ sensor and the wired commercial NEOFOX probe. Corresponding arterial $\mathrm{pO}_{2}\left(\mathrm{paO}_{2}\right)$, blood hemoglobin $\mathrm{O}_{2}$ saturation $\left(\mathrm{SpO}_{2}\right)$ and $\mathrm{FiO}_{2}$ readings are provided. $\mathbf{f}$, The stepwise reduction in $\mathrm{FiO}_{2}$ resulted in corresponding stepwise reductions in tissue pO $\mathrm{O}_{2}$ readings that showed excellent concordance between the wireless $\mathrm{O}_{2}$ sensor and the commercial probe. Corresponding paO $\mathrm{S}_{2} \mathrm{SpO}_{2}$ and $\mathrm{FiO}_{2}$ readings are provided. $\mathrm{Note}$ that for FiO $\mathrm{F}_{2}$ values above room air, $\mathrm{SpO}_{2}$ readings are unable to approximate $\mathrm{paO}_{2}$ or tissue $\mathrm{pO}_{2}$ levels.

yielding an $\mathrm{O}_{2}$ resolution better than $5.8 \mathrm{~mm} \mathrm{Hg} \mathrm{Hz}^{-1 / 2}$ across the relevant $\mathrm{O}_{2}$ range of interest $(<100 \mathrm{~mm} \mathrm{Hg})$. Because the system $\Phi$ resolution is dominated by jitter noise of the AFE and the luminescence intensity increases with a decreasing $\mathrm{O}_{2}$ concentration, the system SNR and hence $\Phi$ resolution improve for lower $\mathrm{O}_{2}$ levels.

The sensor $\mathrm{O}_{2}$ response is reversible (Fig. 4g). A calibration curve converts system phase output to $\mathrm{O}_{2}$ concentration (partial pressure of $\mathrm{O}_{2}, \mathrm{pO}_{2}$ ) (Supplementary Fig. 5). The sensor response times (the time required to reach $90 \%$ of the steady-state value) before black silicone encapsulation from $\sim 3.5$ to $\sim 156 \mathrm{~mm} \mathrm{Hg} \mathrm{O}_{2}$ and vice versa were $\sim 210 \mathrm{~s}$ and $\sim 257 \mathrm{~s}$, respectively; this increased to $\sim 250$ s and $\sim 320$ s after black silicone encapsulation.

The wireless sensors were sterilized in ethylene oxide, and their $\mathrm{O}_{2}$ response was tested to assess the potential effect of sterilization on sensor functionality. The sensor $\mathrm{O}_{2}$ response was nearly identical 


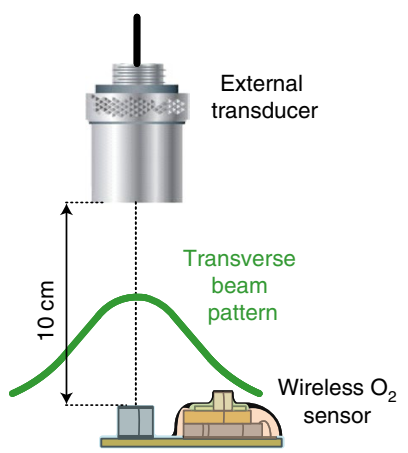

d

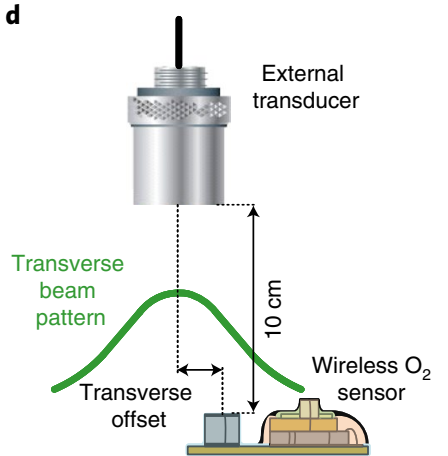

g

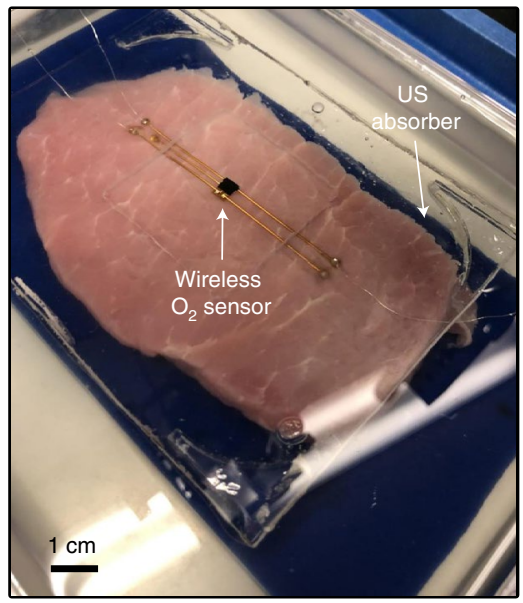

b

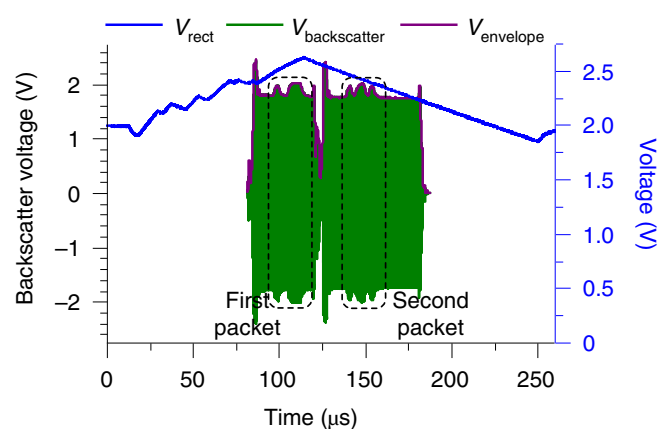

e

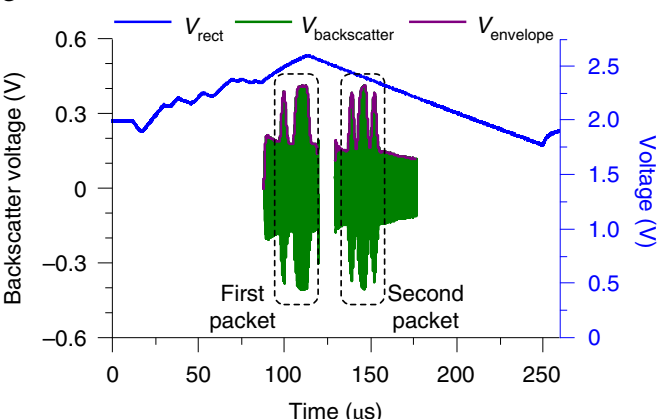

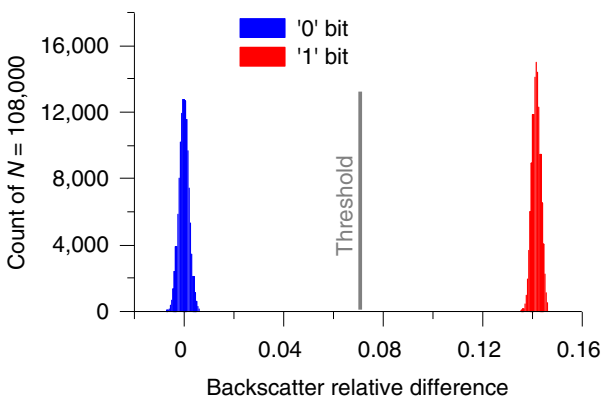

f

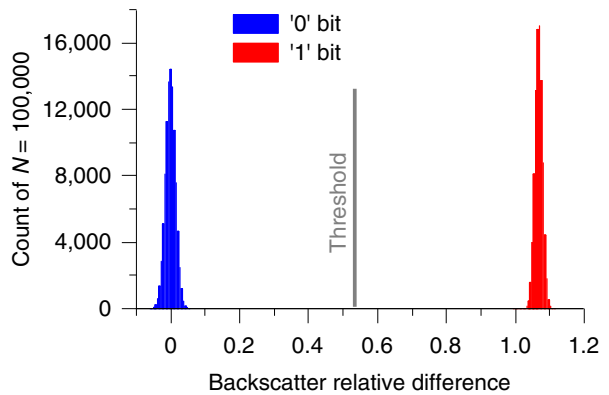

h
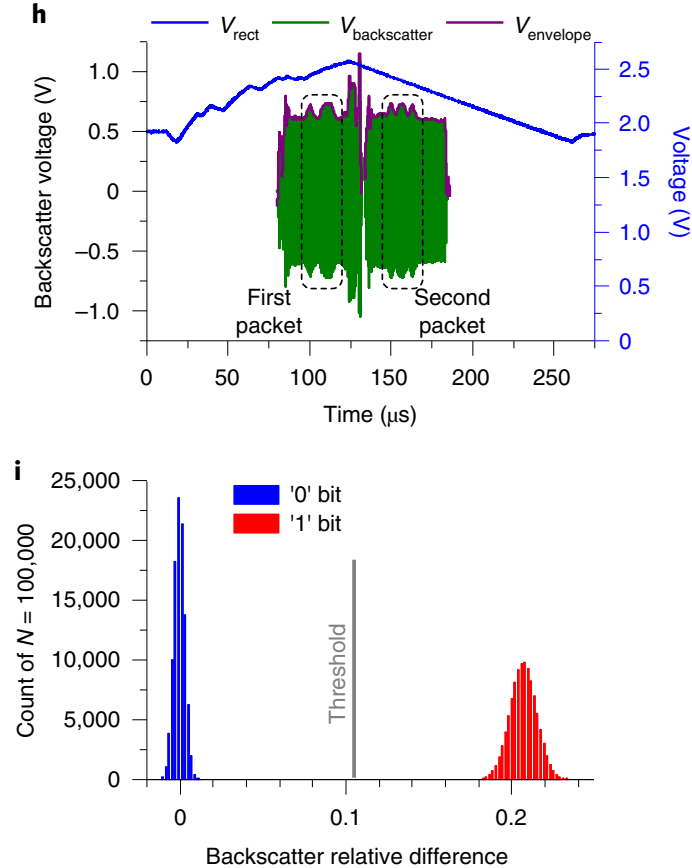

Fig. 6 | In vitro and ex vivo uplink characterization of the wireless $\mathbf{O}_{2}$-sensing system. $\mathbf{a}$,d, Wireless sensor operation at a 10-cm depth in distilled water without (a) and with (d) an intentional transverse offset of the central axis of the acoustic field to that of the sensor's piezo. b,e, Sensor waveform and backscatter signal were captured in the wireless measurement of a single $\mathrm{O}_{2}$ sample for the sensor operated in vitro at a 10-cm depth without (b) and with (e) a transverse misalignment. c,f, Backscatter relative difference for wirelessly recorded $\mathrm{O}_{2}$ samples $(\geq 100,000)$ from the sensor operated in vitro at a $10-\mathrm{cm}$ depth without (c) and with (f) a transverse misalignment. $\mathbf{g}$, The $\mathrm{O}_{2}$ sensor was wirelessly operated at a 10-cm depth through an inhomogeneous sample of fresh, ex vivo porcine tissue, in which acoustic waves passed through approximately $3 \mathrm{~mm}$ of US gel, $1 \mathrm{~mm}$ of skin, $1 \mathrm{~mm}$ of fat and $95 \mathrm{~mm}$ of muscle tissue; scale bar, $1 \mathrm{~cm}$. h. Sensor waveform and backscatter signal were recorded in the wireless measurement of a single $\mathrm{O}_{2}$ sample for the sensor operated at a 10-cm depth through a porcine specimen. $\mathbf{i}$, Backscatter relative difference for $100,000 \mathrm{O}_{2}$ samples, showing $21 \% \mathrm{MD}$ from the sensor operated at a 10-cm depth through a porcine tissue specimen. The system achieved an uplink BER $<10^{-5}$ in the measurement.

before and after sterilization (Fig. 4h), indicating that these sensors are sterilizable without loss of their functionality.

To evaluate the sensor's ability to resist in vivo biofouling, we conducted in vitro experiments in PBS and undiluted human serum.
Human serum, a complex fluid containing hundreds of different proteins ${ }^{29}$, was chosen to simulate in vivo fouling because non-specific protein adsorption (fouling) on the implant surface is considered the initial step in triggering a foreign body reaction ${ }^{30}$ 
and one of the critical factors causing the failure of many implants ${ }^{31}$. The sensors incubated in PBS and serum at $37^{\circ} \mathrm{C}$ for $10 \mathrm{~d}$ demonstrated no apparent loss of $\mathrm{O}_{2}$ sensitivity (Fig. 4i).

The wireless system accurately reflects tissue oxygenation in a physiologically relevant large animal model. We next tested the clinical utility of the wireless direct $\mathrm{O}_{2}$-monitoring system in a physiologically relevant large animal model. Anesthetized juvenile or adult sheep ( $n=2$ animals) were intubated and mechanically ventilated. The biceps femoris was carefully dissected, and both the wireless sensor and a commercial wired $\mathrm{pO}_{2}$ sensor (NEOFOX) were placed below the muscle layer; the muscle and overlying skin were carefully closed (Fig. $5 \mathrm{a}-\mathrm{c}$ ). The US transducer, attached to a five-axis micromanipulator for fine alignment, was placed on top of the skin layer on an acoustic standoff pad (Fig. 5d).

As seen from the data (from animal A) in Fig. 5e and as determined by the wired $\mathrm{pO}_{2}$ sensor, acutely adjusting the inspired $\mathrm{O}_{2}$ concentration from $100 \%$ to $10 \%$ resulted in a rapid reduction in muscle $\mathrm{pO}_{2}$ from approximately $90 \mathrm{~mm} \mathrm{Hg}$ to around $20 \mathrm{~mm} \mathrm{Hg}$. Similarly, the wireless sensor was able to accurately reflect muscle $\mathrm{pO}_{2}$ levels.

More gradual, stepwise reductions in $\mathrm{FiO}_{2}$ content resulted in more gradual reductions in tissue $\mathrm{pO}_{2}$, which were accurately determined by our wireless sensor in real time with similar kinetics to those of the commercial wired probe (Fig. 5f; data from animal B). Importantly, simultaneous determination of blood hemoglobin saturation via pulse oximetry was not capable of detecting differences in tissue or blood oxygenation above room air (21\%), as all hemoglobin is fully saturated beyond this point.

In sum, our wireless $\mathrm{O}_{2}$ sensor system accurately reflects tissue oxygenation status under physiological states and therefore has potential to augment clinical decision making in settings where tissue or an individual's oxygenation status warrants careful monitoring.

The system demonstrates robust wireless operation both in vitro and ex vivo with the implant operated at a $10-\mathrm{cm}$ depth. To further evaluate uplink performance, the system was operated at $350 \mathrm{~Hz} f_{\mathrm{s}}$ and a $10-\mathrm{cm}$ depth in distilled water with and without intentional misalignment and through fresh, ex vivo porcine tissue (which presents inhomogeneous acoustic properties) (Fig. 6). The system, while operating without any misalignment and using a $2-\mathrm{MHz}$ acoustic field with an $I_{\text {SPTA }}$ of $282 \mathrm{~mW} \mathrm{~cm}^{-2}$, exhibited an MD of over $14 \%$, a BER $<10^{-5}$ and an US link PTE of $\sim 0.74 \%$. When operated with an intentional transverse offset of $\sim 1.21 \mathrm{~mm}$ between the central axes of the acoustic field and the sensor piezo, the system demonstrated an MD of $~ 108 \%$ and a BER $<10^{-5}$, but at the expense of a $\sim 58.9 \%$ increase in $I_{\mathrm{SPTA}}$, resulting in a concomitant reduction in the US link PTE. The MD increase was mainly due to reduced reflections from non-responsive regions of the sensor, indicating that an acoustic field with a smaller transverse beam-spot size (that is, comparable to the piezo size) can provide more robust uplink performance and higher US link PTE.

In the ex vivo measurement, the external transducer generated US waves with $706 \mathrm{~mW} \mathrm{~cm}^{-2} I_{\text {SPTA }}$ derated by $0.3 \mathrm{~dB} \mathrm{~cm}^{-1} \mathrm{MHz}^{-1}$ (FDA standard US attenuation in soft tissue ${ }^{13}$ ), producing $\sim 228 \mathrm{~mW}$ of acoustic power at the transducer surface that propagated through approximately $3 \mathrm{~mm}$ of US gel and $97 \mathrm{~mm}$ of tissue. The system achieved a $\sim 21 \% \mathrm{MD}$ and a BER $<10^{-5}$, demonstrating a robust uplink, and a US link PTE of $\sim 0.08 \%$ with the sensor consuming $\sim 194 \mu \mathrm{W}$ of average electrical power. Note that system uplink performance (MD and BER) depends on acoustic attenuation in heterogeneous tissue, which varies for different tissue types and specimens. This is because acoustic absorption and dispersion may change the amplitude of the unmodulated backscatter signal received by the external transceiver during the time interval within which the uplink data are received. Furthermore, US link PTE also depends on acoustic attenuation; for example, the system operated through a porcine tissue specimen exhibited a significantly lower link PTE than the system operated in water because the tissue sample has much higher US attenuation than that of water.

\section{Discussion}

This work presents the miniaturization of a fully implantable optrode in the cubic millimeter volume range, which is suitable for deep-tissue measurements. Although the focus of the study is a system for measuring $\mathrm{O}_{2}$ tension in vivo, the fundamental technological achievements open the door to minimally invasive pulse oximetric sensors, $\mathrm{pH}$ sensors and $\mathrm{CO}_{2}$ sensors, among others. Each of these, embodied in ultraminiature deep-tissue systems, would enable new diagnostics.

Regarding the measurement of deep-tissue $\mathrm{O}_{2}$ tension, the application space of the wireless $\mathrm{O}_{2}$-sensing system is vast. Organ transplantation provides a clear example. Monitoring graft oxygenation following organ transplantation is critical, but relies on indirect methods that require skilled operators and provide only intermittent snapshots of tissue perfusion ${ }^{32,33}$. Continuous and reliable monitoring of graft oxygenation following orthotopic liver transplantation, for example, may enable the early detection of graft ischemia due to either hepatic artery thrombosis or graft vascular disease, allowing for timely surgical re-exploration to minimize the risk of graft loss, which could be fatal ${ }^{2,34}$. Importantly, these complications can occur months to years after transplantation ${ }^{35,36}$. Furthermore, more than 5.7 million individuals are admitted annually to intensive care units in the United States ${ }^{37,38}$. Assessment of tissue oxygenation is a fundamental need in this setting. Although the current iteration of our device requires surgical placement, future miniaturization efforts may enable semi-invasive/ vascular approaches for probe placement. Global measures of cardiopulmonary performance, such as cardiac output, $\mathrm{O}_{2}$ delivery or blood pressure, frequently do not reflect local metabolic demands at the organ and tissue levels and can promote excessive fluid loading or inotrope dosing, worsening outcomes ${ }^{39-41}$. An important contributor in this setting is a lack of hemodynamic coherence between the microcirculation and the macrocirculation ${ }^{42}$. Coupling direct measurements of the microcirculation ${ }^{43}$ with direct monitoring of tissue $\mathrm{pO}_{2}$ would greatly augment critical care management approaches.

To clinically adopt the wireless $\mathrm{O}_{2}$-sensing system for the use of chronic in vivo $\mathrm{O}_{2}$ tracking, a number of technical challenges must be addressed. The first challenge is implant localization by an external transceiver, because the postsurgical in vivo position may drift relative to any external fiducials; such movementcanariseduetopressurefromoutsideofthebody, movement or breathing, and scar formation. The in vivo localization before each $\mathrm{pO}_{2}$ measurement can be achieved with a phased-array transceiver that uses US backscatter information first to find and then to track the time-dependent implant position in the body ${ }^{44}$.

A second challenge arises because acoustic attenuation due to absorption and scattering varies between different US propagation paths in heterogeneous tissue; a path with higher attenuation may significantly degrade system power transfer efficiency and data transfer reliability. For example, muscle tissue with a more unevenly distributed intramuscular fat content will exhibit greater acoustic attenuation $^{45}$. Here, an external transceiver with a large-aperture, multi-element transducer array capable of focusing energy to the implant will allow steering of the US beam along a preferred path. Finally, a phased array could also potentially be used to interrogate multiple $\mathrm{O}_{2}$ sensors implanted in different locations of target tissue, in a time-division multiplexing fashion or simultaneously ${ }^{46}$.

Lastly, chronic in vivo use of the wireless $\mathrm{O}_{2}$ sensor will require hermetic packaging to prevent biofluid penetration into the electronic sensor components and the piezocrystal. Traditionally, small implantable housings make use of ceramic or titanium enclosures brazed or microwelded to achieve the required hermeticity. This is an active area of work both commercially and academically; an extensive review was recently published ${ }^{47}$. Acoustic windows for 
efficient ultrasonic energy transfer into ceramic or metallic housings have recently been demonstrated in the literature ${ }^{48}$. For this work, we used biocompatible polymers to encapsulate the implant, given their ease of use for acute and semichronic experiments. It is well known that polymeric materials at these thicknesses are not suitable for long-term in vivo use due to their high water vapor permeability ${ }^{49}$.

\section{Online content}

Any methods, additional references, Nature Research reporting summaries, source data, extended data, supplementary information, acknowledgements, peer review information; details of author contributions and competing interests; and statements of data and code availability are available at https://doi.org/10.1038/ s41587-021-00866-y.

Received: 9 December 2019; Accepted: 19 February 2021; Published online: 29 March 2021

\section{References}

1. Gibbons, R. D., Meltzer, D. \& Duan, N. Waiting for organ transplantation Science 287, 237-238 (2000)

2. Piardi, T. Vascular complications following liver transplantation: a literature review of advances in 2015. World J. Hepatol. 8, 36-57 (2016).

3. Marland, J. R. K. et al. Real-time measurement of tumour hypoxia using an implantable microfabricated oxygen sensor. Sensing and Bio-Sensing Research 30, 100375 (2020).

4. Peterson, J. I., Fitzgerald, R. V. \& Buckhold, D. K. Fiber-optic probe for in vivo measurement of oxygen partial pressure. Anal. Chem. 56, 62-67 (1984).

5. Liu, S. et al. Quantitative tissue oxygen measurement in multiple organs using 19F MRI in a rat model. Magn. Reson. Med. 66, 1722-1730 (2011).

6. Elas, M. et al. Electron paramagnetic resonance oxygen images correlate spatially and quantitatively with oxylite oxygen measurements. Clin. Cancer Res. 12, 4209-4217 (2006)

7. Gómez, H. et al. Use of non-invasive NIRS during a vascular occlusion test to assess dynamic tissue $\mathrm{O}_{2}$ saturation response. Intensive Care Med. 34, 1600-1607 (2008).

8. Lynch, J. M. et al. Noninvasive optical quantification of cerebral venous oxygen saturation in humans. Acad. Radiol. 21, 162-167 (2014).

9. Zhang, $H$. et al. Wireless, battery-free optoelectronic systems as subdermal implants for local tissue oximetry. Sci. Adv. 5, eaaw0873 (2019).

10. Seo, D. et al. Wireless recording in the peripheral nervous system with ultrasonic neural dust. Neuron 91, 529-539 (2016).

11. Piech, D. K. et al. A wireless millimetre-scale implantable neural stimulator with ultrasonically powered bidirectional communication. Nat. Biomed. Eng. 4, 207-222 (2020)

12. Thimot, J. \& Shepard, K. L. Bioelectronic devices: wirelessly powered implants. Nat. Biomed. Eng. 1, 0051 (2017).

13. O'Leary, B. \& Vaezy, S. Marketing clearance of diagnostic ultrasound systems and transducers. https://www.fda.gov/media/71100/download (US Food and Drug Administration, 2019).

14. IEEE standard for safety levels with respect to human exposure to radio frequency electromagnetic fields, $3 \mathrm{kHz}$ to $300 \mathrm{GHz}$. IEEE Std C95.1-2005 (Revision of IEEE Std C95.1-1991) 1-238 (2006).

15. Ammi, A. Y. et al. Characterization of ultrasound propagation through ex-vivo human temporal bone. Ultrasound Med. Biol. 34, 1578-1589 (2008)

16. Maleki, T. et al. An ultrasonically powered implantable micro-oxygen generator (IMOG). IEEE Trans. Biomed. Eng. 58, 3104-3111 (2011).

17. Kim, A. et al. An implantable ultrasonically-powered micro-light-source ( $\mu$ Light) for photodynamic therapy. Sci. Rep. 9, 1395 (2019).

18. Sonmezoglu, S. \& Maharbiz, M. M. A $4.5 \mathrm{~mm} 3$ deep-tissue ultrasonic implantable luminescence oxygen sensor. In 2020 IEEE International SolidState Circuits Conference (ISSCC) 454-456 (2020).

19. Yao, L., Khan, R., Chodavarapu, V. P., Tripathi, V. S. \& Bright, F. V. Sensitivity-enhanced CMOS phase luminometry system using xerogel-based sensors. IEEE Trans. Biomed. Circuits Syst. 3, 304-311 (2009).

20. McDonagh, C. et al. Phase fluorometric dissolved oxygen sensor. Sens. Actuators B Chem. 74, 124-130 (2001).

21. Wang, X. \& Wolfbeis, O. S. Optical methods for sensing and imaging oxygen: materials, spectroscopies and applications. Chem. Soc. Rev. 43, 3666-3761 (2014)

22. Holland, R. Resonant properties of piezoelectric ceramic rectangular parallelepipeds. J. Acoust. Soc. Am. 43, 988-997 (1968).
23. Chan, C.-M., Chan, M.-Y., Zhang, M., Lo, W. \& Wong, K.-Y. The performance of oxygen sensing films with ruthenium-adsorbed fumed silica dispersed in silicone rubber. Analyst 124, 691-694 (1999).

24. Jorge, P. A. S., Caldas, P., Rosa, C. C., Oliva, A. G. \& Santos, J. L. Optical fiber probes for fluorescence based oxygen sensing. Sens. Actuators B Chem. 103, 290-299 (2004).

25. Hartmann, P., Leiner, M. J. P. \& Kohlbacher, P. Photobleaching of a ruthenium complex in polymers used for oxygen optodes and its inhibition by singlet oxygen quenchers. Sens. Actuators B Chem. 51, 196-202 (1998).

26. Guo, J. \& Sonkusale, S. A $65 \mathrm{~nm}$ CMOS digital phase imager for time-resolved fluorescence imaging. IEEE J. Solid-State Circuits 47, 1731-1742 (2012).

27. Ghanbari, M. M. et al. A sub-mm3 ultrasonic free-floating implant for multi-mote neural recording. IEEE J. Solid-State Circuits 54, 3017-3030 (2019)

28. Kino, G. S. Acoustic Waves: Devices, Imaging, and Analog Signal Processing. (Prentice Hall, 1987).

29. Adkins, J. N. et al. Toward a human blood serum proteome: analysis by multidimensional separation coupled with mass spectrometry. Mol. Cell. Proteomics 1, 947-955 (2002).

30. Ratner, B. D. Replacing and renewing: synthetic materials, biomimetics, and tissue engineering in implant dentistry. J. Dent. Educ. 65, 1340-1347 (2001).

31. Blaszykowski, C., Sheikh, S. \& Thompson, M. Surface chemistry to minimize fouling from blood-based fluids. Chem. Soc. Rev. 41, 5599-5612 (2012).

32. Norton, P. T., DeAngelis, G. A., Ogur, T., Saad, W. E. \& Hagspiel, K. D. Noninvasive vascular imaging in abdominal solid organ transplantation. Am. J. Roentgenol. 201, W544-W553 (2013).

33. Boraschi, P., Pina, M. C. D. \& Donati, F. Graft complications following orthotopic liver transplantation: role of non-invasive cross-sectional imaging techniques. Eur. J. Radiol. 85, 1271-1283 (2016).

34. Hickman, P. E., Potter, J. M. \& Pesce, A. J. Clinical chemistry and post-liver-transplant monitoring. Clin. Chem. 43, 1546-1554 (1997).

35. Mitchell, R. N. Graft vascular disease: immune response meets the vessel wall. Annu. Rev. Pathol. 4, 19-47 (2009).

36. Khaja, M. S., Matsumoto, A. H. \& Saad, W. E. Complications of transplantation. Part 1: renal transplants. Cardiovasc. Intervent. Radiol. 37, 1137-1148 (2014).

37. Wunsch, H., Angus, D. C., Harrison, D. A., Linde-Zwirble, W. T. \& Rowan, K. M. Comparison of medical admissions to intensive care units in the United States and United Kingdom. Am. J. Respir. Crit. Care Med. 183, 1666-1673 (2011)

38. Barrett, M. L., Smith, M. W., Elixhauser, A., Honigman, L. S. \& Pines, J. M. Utilization of intensive care services, 2011: statistical brief \#185. In Healthcare Cost and Utilization Project (HCUP) Statistical Briefs (Agency for Healthcare Research and Quality (US), 2006).

39. Dyson, A. \& Singer, M. Tissue oxygen tension monitoring: will it fill the void? Curr. Opin. Crit. Care 17, 281-289 (2011).

40. Brandstrup, B. et al. Effects of intravenous fluid restriction on postoperative complications: comparison of two perioperative fluid regimens: A randomized assessor-blinded multicenter trial. Ann. Surg. 238 , 641-648 (2003)

41. Dünser, M. W. et al. Association of arterial blood pressure and vasopressor load with septic shock mortality: a post hoc analysis of a multicenter trial. Crit. Care 13, R181 (2009)

42. Ince, $\mathrm{C}$. Hemodynamic coherence and the rationale for monitoring the microcirculation. Crit. Care 19, S8 (2015).

43. Kara, A., Akin, S. \& Ince, C. Monitoring microcirculation in critical illness. Curr. Opin. Crit. Care 22, 444-452 (2016).

44. Wang, M. L., Chang, T. C. \& Arbabian, A. Ultrasonic implant localization for wireless power transfer: active uplink and harmonic backscatter. In 2019 IEEE International Ultrasonics Symposium (IUS) 818-821 (2019).

45. Koch, T. et al. Ultrasound velocity and attenuation of porcine soft tissues with respect to structure and composition: I. Muscle. Meat Sci. 88, 51-58 (2011)

46. Wang, M. L. et al. Closed-loop ultrasonic power and communication with multiple miniaturized active implantable medical devices. In 2017 IEEE International Ultrasonics Symposium (IUS) 1-4 (2017).

47. Shen, K. \& Maharbiz, M. M. Ceramic packaging for neural implants. J. Neural Eng. 18, 025002 (2021)

48. Shen, K. \& Maharbiz, M. M. Design of ceramic packages for ultrasonically coupled implantable medical devices. IEEE Trans. Biomed. Eng. 67, 2230-2240 (2020)

49. Song, E., Li, J., Won, S. M., Bai, W. \& Rogers, J. A. Materials for flexible bioelectronic systems as chronic neural interfaces. Nat. Mater. 19, 590-603 (2020)

Publisher's note Springer Nature remains neutral with regard to jurisdictional claims in published maps and institutional affiliations.

(c) The Author(s), under exclusive licence to Springer Nature America, Inc. 2021 


\section{Methods}

Fabrication of the $\mathbf{O}_{2}$-sensing film. Film fabrication included two steps. First, a luminescent dye, tris-(bathophenanthroline) ruthenium (II) perchlorate $\left(\mathrm{Ru}(\mathrm{dpp})_{3}\left(\mathrm{ClO}_{4}\right)_{2}\right)(75213-31-9$, GFS Chemicals), was immobilized on the surface of silica particles (LiChrosorb Si $100(10 \mu \mathrm{m})$; 7631-86-9, Sigma-Aldrich) at a $\sim 1: 10$ dye:particle ratio by weight. Briefly, $200 \mathrm{mg}$ of $\mathrm{Ru}(\mathrm{dpp})_{3}\left(\mathrm{ClO}_{4}\right)_{2}$ complex was dissolved in $10 \mathrm{ml}$ of ethanol (ACS reagent $\geq 99.5 \%$; 459844, Sigma-Aldrich). Silica gel was prepared by adding $2 \mathrm{~g}$ of silica particles to $40 \mathrm{ml}$ of aqueous sodium hydroxide solution $(0.01 \mathrm{~N} ; 1310-73-2$, Thermo Fisher Scientific) and magnetically stirring the mixture at 1,000 r.p.m. for $30 \mathrm{~min}$. Next, the dye-containing ethanol solution was poured into the silica gel solution and stirred at 1,000 r.p.m. for $30 \mathrm{~min}$. The dye-containing silica particles were filtered out of the solution through a filter with a pore size of $0.45 \mu \mathrm{m}$ (165-0045, Thermo Fisher Scientific), washed once in ethanol and three times in deionized water. All of the supernatant was removed, and the dye-loaded silica particles were dried at $70^{\circ} \mathrm{C}$ overnight.

Second, the dye-loaded silica particles were incorporated into PDMS to avoid problems related to dye leaching in aqueous media. Note that PDMS was selected as the polymer matrix due to its excellent $\mathrm{O}_{2}$ permeability, biocompatibility, optical transparency and high solubility for the fillers, preventing agglomeration ${ }^{50}$ Dried silica particles $(2 \mathrm{~g})$ were thoroughly mixed with $20 \mathrm{~g}$ of PDMS prepolymer part A and $2 \mathrm{~g}$ of PDMS curing agent part B (Sylgard 184, Dow Corning). A $\sim 100-\mu \mathrm{m}$-thick film was prepared by spinning a small amount of this mixture at 500 r.p.m. on a microscope slide and curing it at $60^{\circ} \mathrm{C}$ under vacuum $(<10$ torr) in the dark for $\sim 7 \mathrm{~d}$ to remove the solvent and air bubbles. The cured film was kept in the dark at room temperature for at least $24 \mathrm{~h}$ before use and was stored in the dark at room temperature. Note that the amount of silica particles in PDMS and the film thickness were adjusted to maintain a reasonable trade-off between luminescence intensity and $\mathrm{O}_{2}$ response time $\mathrm{e}^{23,51}$

Design, fabrication and assembly of the wireless sensor. The sensor (implant) was built on a $100-\mu \mathrm{m}$-thick polyimide, flexible PCB with electroless nickel/immersion gold coating (Rigiflex Technology). A 750- $\mu$ m-thick PZT sheet with silver electrodes was diced using a dicing saw with a $300-\mu \mathrm{m}$-thick ceramic-cutting blade. A PZT cube $\left(750 \mu \mathrm{m}^{3}\right)$ was first attached to a PCB using two-part conductive silver epoxy with a 1:1 mix ratio (8331, MG Chemicals), and the board was cured at $65^{\circ} \mathrm{C}$ for $15 \mathrm{~min}$, well below the PZT Curie temperature and melting temperature of polyimide. The PZT top electrode was wire bonded to the PCB using a wedge bonder (747677E, West Bond) to create an electrical connection between the PZT and IC. The board was encapsulated with $\sim 10$ - $\mu$ m-thick parylene- $C$ using chemical vapor deposition (Specialty Coating Systems) to insulate the piezocrystal from the environment due to its biological inertness and resistance to moisture ${ }^{52}$. For the IC and its wire bonds, the PCB's open metal pads were carefully exposed by scoring the parylene around the pads using a sharp probe tip and removing the parylene layer. The IC was attached to the PCB using the same silver epoxy, cured at $65^{\circ} \mathrm{C}$ for $15 \mathrm{~min}$ and wire bonded to the PCB. Next, a $\sim 250-\mu$ m-thick optical filter (Edmund Optics) was attached to the top of the IC using medical-grade UV-curable epoxy (OG142, Epotek). The same UV-curable epoxy was also used to assemble other sensor components, including a $650 \times 350 \times 200 \mu \mathrm{m}^{3} \mu \mathrm{LED}$ (APG0603PBC, Kingbright) and its 3D-printed holder (Protolabs), and to protect and insulate the wire bonds of the chip and $\mu \mathrm{LED}$. After assembly, the $\mathrm{O}_{2}$-sensing film was slipped through the gap between the $\mu$ LED holder and the optical filter. The small residual space between the $\mu$ LED holder and the film was filled with PDMS (Sylgard 184, Dow Corning). PDMS parts A and B were mixed in a 10:1 ratio, degassed, poured between the space and cured at room temperature for $48 \mathrm{~h}$. Finally, the $\mathrm{O}_{2}$-sensing region on the sensor surface was coated with a $\sim 180-\mu \mathrm{m}$-thick layer of biocompatible black silicone. The black silicone consisted of two-part, low-viscosity silicone elastomer (MED4-4220, NuSil Technology) and black, single-component masterbatch (Med-4900-2, NuSil Technology); the two silicone parts were first mixed in a 1:1 weight ratio, and the masterbatch ( $4 \%$ by weight) was added, thoroughly mixed, degassed for $<\sim 5 \mathrm{~min}$, applied and cured at room temperature for $48 \mathrm{~h}$.

Here, PZT was selected as a piezoelectric material due to its high electromechanical coupling coefficient and high mechanical quality factor, providing high power harvesting efficiency. A lead-free biocompatible barium titanate $\left(\mathrm{BaTiO}_{3}\right)$ ceramic with a slightly lower electromechanical coupling coefficient can be used in place of $\mathrm{PZT}^{53}$.

The detection volume of the $\mathrm{O}_{2}$ sensor was estimated from the material volume where $\mathrm{O}_{2}$ molecules diffuse through to the $\mathrm{O}_{2}$-sensing film under the $\mu L E D$. The implant volume was measured by suspending the implant without test leads with a thin, rigid wire below the water surface in a container placed on an electronic balance with $0.1-\mathrm{mg}$ measurement accuracy. The implant volume was calculated from the weight difference of a water-filled container before and after submersion of the implant in water; the weight difference, equal to the buoyant force, was divided by the water density to determine the actual implant volume. Measurements were performed using two implants; each implant volume was measured five times to determine reproducibility. The obtained data were presented as the mean \pm 2 s.d.

Optical characterization. The absorption spectrum of the $\mathrm{O}_{2}$-sensing film and the transmission spectrum of the optical filter were measured with a spectrophotometer (Jenway 6300). The emission spectra of the film and $\mu$ LED were measured using a CCD spectrometer (Thorlabs, CCS200/M) operating at a 1 -s integration time and enabled with electric dark correction. The film samples were excited at $450 \mathrm{~nm}$ by a laser diode (Osram, PL450B) driven with a Keithley 2400 source meter, and its emission was scanned in the range of 515-800 nm. The $\mu$ LED optical output power was measured using an optical power meter (Thorlabs, PM100D) equipped with an Si photodiode detector (Thorlabs, S121C). The current-voltage curve of the $\mu$ LED was measured with a Keithley 2400 source meter. Photodiode responsivity was characterized using a halogen lamp coupled to a monochromator, a reference photodiode (Thorlabs, FD11A) and an Agilent B2912A source meter. The same photodiode (FD11A) was also used to measure the $\mu$ LED output light intensity.

Photobleaching and leaching tests. Dye photobleaching was evaluated using a fully packaged sensor continuously operated in room air $\left(21 \% \mathrm{O}_{2}\right)$ at room temperature. After the bleaching test, the same sensor was continuously operated in $1 \times$ PBS without calcium and magnesium (Corning, Mediatech) at $37 \pm 0.1^{\circ} \mathrm{C}$ in an oven (TestEquity Model 107) to assess dye leaching and further photobleaching. In the tests, the sensor was driven by differential 2-MHz AC signals from a Keysight 33500B function generator, which are ac-coupled to the IC's rectifier inputs. The transimpedance amplifier (TIA) output (Supplementary Fig. 3) was connected to a buffer (LTC6268, Linear Technology). The buffer output was continuously measured using a 16-bit digitizer (NI myDAQ; National Instruments) with $200-\mathrm{kHz}$ sampling rate. A custom Labview program (Labview 2018, National Instruments) was developed to detect and record the peak-to-peak amplitude of the buffer output that is directly proportional to the Ru-dye luminesce intensity.

Design of the external transceiver. The external transceiver consisted of TX and RX paths. The TX path included a high-voltage pulser with an integrated TX/ RX switch (MAX14808, Maxim Integrated) and a digital controller module (NI PXIe-6363, National Instruments). During the TX mode, the high-voltage pulser converted a low-voltage signal from the digital controller module to a high-voltage signal to drive an external transducer. The RX path included an ultralow noise amplifier (AD8432, Analog Devices) to receive and amplify the backscatter signal from the external transducer, a gain amplifier to further amplify the signal to a level within the input range of the analog-digital converter (ADC) and a digitizer with an antialiasing filter and a 14-bit high-speed ADC (NI PXIe-5122, National Instruments) to filter and digitize the signal after receiving and amplification. In addition to the switch integrated into the pulser, an additional switch (ADG619, Analog Devices) was used to minimize the electrical coupling between the TX and RX paths. TX and RX paths were synchronized using the clock integrated into the backplane of the PXI chassis (NI PXIe-1062Q, National Instruments). The digital controller, digitizer and NI PXIe-8360 modules were inserted in the chassis, in which the NI PXIe-8360 module was used to connect the chassis to a computer for communication with the other modules and data transfer.

A custom Labview program was developed to control the modules and to process the backscatter data in real time. A (TX and RX) communication protocol was encoded in the program. During data processing, the backscatter data digitized by a 14 -bit $\mathrm{ADC}$ with a $20-\mathrm{MHz}$ sampling rate were resampled by a factor of five and then interpolated with a sinc function. The sinc interpolation was followed by peak detection to extract the envelope of the backscatter signal and linear interpolation to increase the number of data points, improving the accuracy in determining an optimal threshold that minimizes BER. An optimal threshold (that is, the half value of the sum of modulated and unmodulated backscatter signal amplitudes) was determined by taking the mean of the data points from the time intervals where the steady-state backscatter signal was amplitude modulated and unmodulated. The threshold was used to convert the digitized data into digital format (bits, ' 0 ' or ' 1 '). The bits were scanned to find a preamble and a postamble and hence to extract $\mathrm{O}_{2}$ data bits. The binary-coded data were converted to numeric data, which were sent to a computer through a serial link for data storage and further analysis.

In vitro and ex vivo characterization. An in vitro characterization of the system (Fig. 4 and Supplementary Figs. 7 and 8) was performed in a custom-built water tank (Supplementary Fig. 9) using a 25.4-mm diameter, 2.25-MHz single-element ultrasonic transducer with a $47.8-\mathrm{mm}$ focal depth (V304-SU-F1.88IN-PTF, Olympus). During measurements, the transducer face was covered with a thin latex sheet by filling the empty space between the transducer face and the latex sheet with castor oil (acting as a coupling medium) to protect the transducer-matching layer from possible damage due to long-term contact with water. A hydrophone (HGL-0400, Onda) was used to calibrate the output pressure and characterize the acoustic beam patterns of the external transducer (see Supplementary Fig. 10 for the beam patterns of the transducers used in this study). An Allan deviation analysis ${ }^{54}$ was used to quantify the system noise performance (Fig. 4).

During measurements, the water tank was placed on a stirring hotplate (Thermo Scientific Cimarec) to keep the water temperature constant at $37 \pm 0.1^{\circ} \mathrm{C}$ and to stir the water to increase the speed of transition from a low to high $\mathrm{O}_{2}$ level in distilled water and vice versa. The water $\mathrm{O}_{2}$ concentration was monitored using a commercial $\mathrm{O}_{2}$ probe with a $300-\mu \mathrm{m}$ core diameter (NEOFOX-KIT-PROBE; 
BIFBORO-300-2; Ocean Optics) and was varied by controlling the ratio of $\mathrm{O}_{2}$ and $\mathrm{N}_{2}$, which were supplied to the water tank through two pipes via two identical gas flow controllers (FMA-A2407, Omega) connected to $\mathrm{O}_{2}$ and $\mathrm{N}_{2}$ gas cylinders. A custom Matlab program controlled the flow controllers through a digital-analog converter (NI myDAQ, National instruments).

Ethylene oxide sterilization with an exposure time of $4 \mathrm{~h}$ at $37 \pm 3{ }^{\circ} \mathrm{C}$ and an aeration time of $24 \mathrm{~h}$ at $37 \pm 3^{\circ} \mathrm{C}$ was performed by a commercial vendor (Blue Line Sterilization Services).

To assess the functionality of the wireless $\mathrm{O}_{2}$ sensors over time in an environment that mimics (to first order) in vivo biofouling, sensors were incubated with $1 \times$ PBS without calcium and magnesium (Corning, Mediatech) and pooled human serum (off the clot) (Innovative Research) for $10 \mathrm{~d}$ at $37 \pm 0.1^{\circ} \mathrm{C}$ in an oven (TestEquity Model 107). Two antibiotics, penicillin $\left(100 \mathrm{U} \mathrm{ml}^{-1}\right)$ and streptomycin $\left(100 \mu \mathrm{g} \mathrm{ml}^{-1}\right)$ (Gibco by Life Technologies, 15-140-122; Thermo Fisher Scientific), were added to human serum to inhibit bacterial growth. The test in serum was performed by placing the sensor in a container, and antibiotic-supplemented serum was replaced every $24 \mathrm{~h}$ to ensure sterile conditions during the study. During testing, the sensors were operated at a $350-\mathrm{Hz}$ sampling rate and differential $2-\mathrm{MHz}$ AC signals were produced by a Keysight $33500 \mathrm{~B}$ function generator, which are ac-coupled to the IC's rectifier inputs. One of the rectifier inputs was connected to a high-input impedance buffer amplifier (LTC6268, Linear Technology). The buffer output, $\mathrm{O}_{2}$ data, was recorded by a 14-bit digitizer (NI PXIe-5122, National Instruments) synchronized to the function generator and a custom Labview program.

Measurements for system uplink performance assessment at a $10-\mathrm{cm}$ depth in distilled water and in a fresh ex vivo porcine specimen were performed with a custom, spherically focused $2-\mathrm{MHz}, 25.4-\mathrm{mm}$ diameter ultrasonic transducer with an 88.1-mm focal length (Sensor Networks; Fig. 6 and Supplementary Fig. 11a). An additional measurement for system uplink performance assessment at a 5 -cm depth in a fresh ex vivo porcine specimen was performed using a 25.4-mm diameter, $2.25-\mathrm{MHz}$ single-element ultrasonic transducer with a $47.8-\mathrm{mm}$ focal depth (V304-SU-F1.88IN-PTF, Olympus; Supplementary Figs. 11b and 12). During measurement, a porcine tissue sample was positioned between the wireless sensor and the external transducer, with coupling enabled by US gel (Aquasonic Clear; Parker Labs). Air bubbles in the US gel were removed via centrifugation at 2,800 r.p.m. for $10 \mathrm{~min}$. To remove possible air bubbles entrapped between the sensor and the tissue, the sensor was positioned on a tissue sample in a container filled with distilled water. An US absorber was placed under the tissue sample to avoid US reflection from the container bottom interface.

Backscatter modulation depth. Backscatter relative difference (BRD) is defined as the ratio of the amplitude difference between the modulated and unmodulated backscatter signals to the amplitude of the unmodulated backscatter signal. The MD percentage was calculated by multiplying the BRD by 100 . BRD plots were obtained by collecting data samples from time points where the steady-state backscatter signal was amplitude modulated and unmodulated during $\mathrm{O}_{2}$ measurement.

In vivo measurements. The Committee on Animal Research of the University of California, San Francisco, approved all protocols and procedures. All animal research conforms to the National Institutes of Health (NIH) guidelines as outlined in the Guide for the Care and Use of Laboratory Animals.

Lambs (2-12 weeks of age) were given ketamine (10-15 $\mathrm{mg} \mathrm{kg}^{-1}$, intramuscularly), and an appropriately sized catheter was placed percutaneously into a peripheral vein. The lambs were given intravenous (IV) boluses of fentanyl citrate and diazepam for sedation and anesthetized with continuous IV infusions of fentanyl citrate, ketamine hydrochloride and diazepam. Heart rate and blood pressure were continuously monitored, and doses were adjusted with any changes in these parameters. Catheters were placed in an artery and vein of each hind limb. This procedure was done either before or after endotracheal intubation when a surgical plane of anesthesia was present. Lambs were intubated with a 4.5-7.5-mm OD cuffed endotracheal tube and mechanically ventilated with a pediatric time-cycled, pressure-limited ventilator. Vecuronium bromide was given intermittently (IV bolus) for muscle relaxation and redosed for movement. Ventilation with $21 \% \mathrm{O}_{2}$ was adjusted to maintain a systemic arterial $\mathrm{pCO}_{2}$ between 35 and 45 torr. To ensure that lambs were adequately anesthetized during paralysis, heart rate, systemic arterial pressure, temperature and response to stimuli were continuously monitored. In addition, arterial blood gas readings were performed every $30-120 \mathrm{~min}$ to determine $\mathrm{pCO}_{2}, \mathrm{pO}_{2}$ and $\mathrm{pH}$ parameters.

Following instrumentation, animals were allowed to recover to steady state until they required no further adjustment to sedatives and exhibited stable hemodynamic parameters. This time was designated as the normoxic baseline, and blood gas analysis was performed to confirm physiologic parameters.

To facilitate $\mathrm{O}_{2}$ sensor placement, a two-way skin flap of an appropriate size was created over the lateral thigh. The uppermost layers of skin were carefully dissected away from the subcutaneous space to ensure tissue integrity and were then reflected away from the site. Exposure of the posterior fascial compartment was then visualized and dissected away to reveal the biceps femoris muscle. Because of muscle depth, the lateral aspect of the biceps femoris was carefully dissected to create a tunnel into the underlying fascial plane. The wireless $\mathrm{O}_{2}$ sensor was then seated under the biceps femoris via the created tunnel, and the skin was closed in a simple continuous fashion. The wireless $\mathrm{O}_{2}$ sensor had five flexible leads used only for electrical testing and debugging before in vivo measurements, and, as seen in Fig. 5, they were not accessible from the outside except two leads (ground and $\left.V_{\text {DC-DC }}\right)$ in the in vivo measurements, which were used to check the sensor functionality after implantation and were completely disconnected during measurements. A wired $\mathrm{O}_{2}$ probe (NEOFOX-KIT-PROBE; BIFBORO-300-2; Ocean Optics) was placed nearby to confirm tissue $\mathrm{pO}_{2}$ measurements. Tissue $\mathrm{pO}_{2}$ measurements were compared to $\mathrm{paO}_{2}$ obtained by blood gas analysis as well as with $\mathrm{SpO}_{2}$ obtained via a GE Dash 3000 patient monitor and GE Masimo finger probe placed on the ear.

At the end of the protocol, all lambs were euthanized with a lethal injection of sodium pentobarbital ( $150 \mathrm{mg} \mathrm{kg}^{-1}$ ) followed by bilateral thoracotomy, as described in the National Institutes of Health Guidelines for the Care and Use of Laboratory Animals.

In vivo experiments were performed using a $12.7-\mathrm{mm}$ diameter, $2.25-\mathrm{MHz}$ ultrasonic transducer with a 21.6-mm focal depth (V306-SU-F0.88IN-PTF; Olympus), which demonstrated similar beam patterns with the 25.4 -mm diameter transducer used in the in vitro experiments (Supplementary Fig. 10). The transducer output pressure and acoustic intensity were characterized in distilled water using a hydrophone (HGL-0400; Onda) after its face was covered with castor oil and a thin latex sheet to protect its matching layer from possible damage due to long-term direct contact with US gel. The external transducer was attached to a custom five-axis micromanipulator built using single-axis linear stages (DT100 X; SD Instruments), a tilting stage (MM-2A; Newport) and a 0.5-mm acrylic sheet. The micromanipulator stage, used for alignment of the external transducer to the implanted sensor, was placed on top of the skin layer on a 7-mm-thick acoustic standoff pad (DIY ultrasound phantom gel; Humimic Medical) with US gel (Aquasonic Clear; Parker Labs) applied to the skin surface and the external transducer for acoustic coupling. The US backscatter amplitude (Supplementary Fig. 13) was used for fine alignment of the implant and the external transducer.

Tissue $\mathrm{pO}_{2}$ measurements were performed with the wireless system operated at a sampling rate of 350 samples per second. In the in vivo measurements (Fig. 5 and Supplementary Fig. 11c-e), the maximum distance from the external transducer to the wireless $\mathrm{O}_{2}$ sensor, operated with an acoustic field that had a derated $I_{\text {SPTA }}$ of $454 \mathrm{~mW} \mathrm{~cm}^{-2}$ and a mechanical index of 0.08 (both below the FDA regulatory limits of $720 \mathrm{~mW} \mathrm{~cm}^{-2}$ and 0.19 , respectively), was $\sim 26 \mathrm{~mm}$, with $\sim 19 \mathrm{~mm}$ consisting of tissue (including skin, fat and muscle). The distance between the implanted sensor and the external transducer was estimated from the $2 \mathrm{ToF}$ (that is, the time delay between the received backscatter signal from the sensor piezo and the signal that drove the external transducer). The data from the wireless $\mathrm{O}_{2}$ sensor and the wired $\mathrm{O}_{2}$ probe, shown in Fig. 5, were averaged every 5 s. Two identical wireless $\mathrm{O}_{2}$ sensors were used in the in vivo measurements; the first sensor $\mathrm{O}_{2}$ responses in water and animal $\mathrm{A}$ are shown in Figs. $4 \mathrm{e}$ and 5e, respectively, and the second sensor $\mathrm{O}_{2}$ responses in water and animal B are shown in Supplementary Fig. 14 and Fig. 5f. All images were captured by a smartphone camera.

Reporting Summary. Further information on research design is available in the Nature Research Reporting Summary linked to this article.

\section{Data availability}

All data supporting the results in this study are available within the article or its Supplementary Information.

\section{Code availability}

The custom Labview program and Matlab code used in this study are available on Github at https://github.com/ssonmezoglu/NBT-21.

\section{References}

50. Pfeiffer, S. A. \& Nagl, S. Microfluidic platforms employing integrated fluorescent or luminescent chemical sensors: a review of methods, scope and applications. Methods. Appl. Fluoresc. 3, 034003 (2015)

51. Lu, X., Manners, I. \& Winnik, M. A. Polymer/silica composite films as luminescent oxygen sensors. Macromolecules 34, 1917-1927 (2001).

52. Hassler, C., Boretius, T. \& Stieglitz, T. Polymers for neural implants. J. Polym. Sci. B Polym. Phys. 49, 18-33 (2011).

53. Chang, T. C. et al. Design of tunable ultrasonic receivers for efficient powering of implantable medical devices with reconfigurable power loads. IEEE Trans. Ultrason. Ferroelectr. Freq. Control 63, 1554-1562 (2016).

54. El-Sheimy, N., Hou, H. \& Niu, X. Analysis and modeling of inertial sensors using allan variance. IEEE Trans. Instrum. Meas. 57, 140-149 (2008).

\section{Acknowledgements}

This work was supported by the Chan Zuckerberg Biohub (CZB) (to M.M.M.) and by NIH/NICHD R44HD094414 and R01HD072455 (to J.R.F. and E.M.). We thank C. Losser, R. Hutchings and C. Vento for expert assistance with animal handling and surgery as well as members of the Laboratory Animal Resource Center (LARC) at the University 
of California, San Francisco. We also thank the Berkeley Wireless Research Center and R. Muller (University of California, Berkeley) for access to IC design software.

\section{Author contributions}

S.S. supervised the project, designed and built the wireless system, designed and performed the in vitro and ex vivo experiments and analyzed and interpreted the associated data. S.S., J.R.F. and E.M. designed and performed the in vivo experiments and interpreted biological data. M.M.M. contributed to the design of the experiments. S.S., E.M. and M.M.M. participated in writing the paper. All authors contributed to the discussion of the paper.

\section{Competing interests}

M.M.M. is an employee of iota Biosciences, Inc., a fully owned subsidiary of Astellas Pharma. All of the other authors declare no competing interests.

\section{Additional information}

Supplementary information The online version contains supplementary material available at https://doi.org/10.1038/s41587-021-00866-y.

Correspondence and requests for materials should be addressed to S.S. or M.M.M. Reprints and permissions information is available at www.nature.com/reprints. 


\section{Reporting Summary}

Nature Research wishes to improve the reproducibility of the work that we publish. This form provides structure for consistency and transparency in reporting. For further information on Nature Research policies, see our Editorial Policies and the Editorial Policy Checklist.

\section{Statistics}

For all statistical analyses, confirm that the following items are present in the figure legend, table legend, main text, or Methods section. n/a Confirmed

$\bigotimes$ The exact sample size $(n)$ for each experimental group/condition, given as a discrete number and unit of measurement

$\square$ A statement on whether measurements were taken from distinct samples or whether the same sample was measured repeatedly

Х The statistical test(s) used AND whether they are one- or two-sided

X Only common tests should be described solely by name; describe more complex techniques in the Methods section.

Х $\square$ A description of all covariates tested

Х $\square$ A description of any assumptions or corrections, such as tests of normality and adjustment for multiple comparisons

$\triangle$ A full description of the statistical parameters including central tendency (e.g. means) or other basic estimates (e.g. regression coefficient)

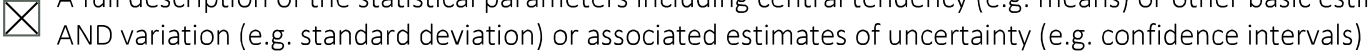

$\triangle$ For null hypothesis testing, the test statistic (e.g. $F, t, r$ ) with confidence intervals, effect sizes, degrees of freedom and $P$ value noted

$\bigotimes \square \begin{aligned} & \text { For null hypothesis testing, the test statistic } \\ & \text { Give } P \text { values as exact values whenever suitable. }\end{aligned}$

Х $\square$ For Bayesian analysis, information on the choice of priors and Markov chain Monte Carlo settings

Х $\square$ For hierarchical and complex designs, identification of the appropriate level for tests and full reporting of outcomes

Х $\square$ Estimates of effect sizes (e.g. Cohen's $d$, Pearson's $r$ ), indicating how they were calculated

\section{Our web collection on statistics for biologists contains articles on many of the points above.}

\section{Software and code}

Policy information about availability of computer code

Data collection Custom Labview programs (Labview 2018; National Instruments) were used to record and process sensor data in real time.

Data analysis Data were analysed by using MATLAB R2018b, Inc. Curve fitting to the experimental data was performed by using the curve-fitting toolbox of MATLAB R2018b, Inc. OriginPro 9.0 was used to plot the data.

For manuscripts utilizing custom algorithms or software that are central to the research but not yet described in published literature, software must be made available to editors and

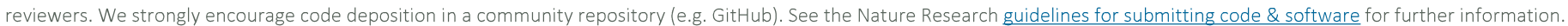

\section{Data}

Policy information about availability of data

All manuscripts must include a data availability statement. This statement should provide the following information, where applicable:

- Accession codes, unique identifiers, or web links for publicly available datasets

- A list of figures that have associated raw data

- A description of any restrictions on data availability

The authors declare that all data supporting the findings of this study are available within the paper and its Supplementary Information. 
Please select the one below that is the best fit for your research. If you are not sure, read the appropriate sections before making your selection.

\ Life sciences

Behavioural \& social sciences

Ecological, evolutionary \& environmental sciences

For a reference copy of the document with all sections, see nature.com/documents/nr-reporting-summary-flat.pdf

\section{Life sciences study design}

All studies must disclose on these points even when the disclosure is negative.

Sample size Animal experiments for this study were performed to demonstrate system capabilities; therefore, no sample size calculation was performed beforehand. The study was carried out with three animal subjects. Quantitative results were collected for two of the animals. Additional subjects were used in pilot studies.

Data exclusions No data were excluded from the analyses.

Replication All attempts at experimental replication were successful when following the sensor fabrication process described in the paper.

Randomization Animals tested were selected randomly. The sensors tested in vitro, ex vivo, and in vivo were fabricated using the same fabrication process as described in the paper.

Blinding Blinding was not relevant to our study, as there were no subjective elements to the assessment of the system capabilities.

\section{Reporting for specific materials, systems and methods}

We require information from authors about some types of materials, experimental systems and methods used in many studies. Here, indicate whether each material, system or method listed is relevant to your study. If you are not sure if a list item applies to your research, read the appropriate section before selecting a response.

\begin{tabular}{l|l} 
Materials \& experimental syste \\
\hline $\mathrm{n} / \mathrm{a}$ & Involved in the study \\
$\square$ & $\square$ Antibodies \\
$\square$ & $\square$ Eukaryotic cell lines \\
$\square$ & $\square$ Palaeontology and archaeology \\
$\square$ & $\square$ Animals and other organisms \\
$\square$ & $\square$ Human research participants \\
$\square$ & $\square$ Clinical data \\
$\searrow$ & $\square$ Dual use research of concern
\end{tabular}

\begin{tabular}{l|l}
\multicolumn{2}{l}{ Methods } \\
\hline n/a & Involved in the study \\
$\square$ & $\square$ ChIP-seq \\
$\searrow$ & $\square$ Flow cytometry \\
$\triangle$ & $\square$ MRI-based neuroimaging
\end{tabular}

\section{Animals and other organisms}

Policy information about studies involving animals; ARRIVE guidelines recommended for reporting animal research

$\begin{array}{ll}\text { Laboratory animals } & \text { Juvenile or adult sheep. } \\ \text { Wild animals } & \text { This study did not involve wild animals. } \\ \text { Field-collected samples } & \text { This study did not involve field-collected samples. } \\ \text { Ethics oversight } & \begin{array}{l}\text { The Committee on Animal Research of the University of California, San Francisco, approved all protocols and procedures. All animal } \\ \text { research conforms to the National Institutes of Health (NIH) guidelines as outlined in the Guide for the Care and Use of Laboratory }\end{array}\end{array}$

Note that full information on the approval of the study protocol must also be provided in the manuscript. 